Discussion Paper No. 12-002

\title{
A Gains from Trade Perspective on Macroeconomic Fluctuations
}

Paul Beaudry and Franck Portier

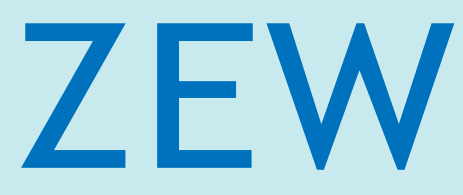

Zentrum für Europäische Wirtschaftsforschung $\mathrm{GmbH}$ Centre for European Economic Research 
Discussion Paper No. 12-002

\title{
A Gains from Trade Perspective on Macroeconomic Fluctuations
}

\author{
Paul Beaudry and Franck Portier
}

Download this ZEW Discussion Paper from our ftp server:

http://ftp.zew.de/pub/zew-docs/dp/dp12002.pdf

Die Discussion Papers dienen einer möglichst schnellen Verbreitung von neueren Forschungsarbeiten des ZEW. Die Beiträge liegen in alleiniger Verantwortung der Autoren und stellen nicht notwendigerweise die Meinung des ZEW dar.

Discussion Papers are intended to make results of ZEW research promptly available to other economists in order to encourage discussion and suggestions for revisions. The authors are solely responsible for the contents which do not necessarily represent the opinion of the ZEW. 


\section{Non-technical summary}

Many modern macroeconomic models either adopt a representative agent setup or introduce heterogeneity among individuals that leads only to trade in assets, while excluding the possibility that agents gain from trading with each other in goods markets. This paper adds the latter aspect into the standard framework by assuming that not all agents are perfect substitutes in the production of goods from different sectors. In other words, not all agents are equally valuable at producing all goods in the short run. Since agents are specialized in the goods they can produce in the short run, this creates a situation where there are explicit gains from trade between individuals.

The baseline model of the paper is a two-sector model, where consumption and investment goods are produced. The main interest lies in knowing when changes in the information set that agents perceive as being relevant for predicting the future may cause booms and busts. An important result of the paper is that when labor in both sectors is perfectly homogeneous, the Walrasian equilibrium of the economy cannot exhibit positive aggregate co-movement, i.e., aggregate consumption, aggregate investment and employment cannot all strictly increase after a positive change in the exogenous component in the agents' information set. The model with homogeneous labor thus fails to generate one of the well-established features of business cycles. It is shown in the paper, however, that the Walrasian equilibrium of the economy can exhibit positive co-movement, if preferences are identical but labor markets are specialized, i.e., there are explicit gains from trade. In such a setting, perception driven positive aggregate co-movement arises if the market for capital is well-behaved, i.e., aggregate capital supply is upward sloping and aggregate capital demand is downward sloping.

Another focus of the paper is on positive policy analysis. First, the conditions are examined, under which fiscal multipliers can be observed. By looking at fiscal policies which are composed only of current government expenditures paid by current taxes and consist of only the purchase of investment goods by the government, it is shown that an increase in public spending tends to crowd out private expenditures when there are no explicit gains from trade. Allowing explicit gains from trade in the model leads, on the other hand, to the opposite result: an increase in government purchases of capital goods leads to an increase in private purchases of consumption goods and create positive co-movement, while leaving private purchases of capital goods relatively untouched. Second, explicit gains from trade is introduced into a standard sticky price model in order to check how the conventional wisdom regarding the determination of inflation and the role of monetary policy in responding to demand shocks is altered. Thus, a simple mechanism is provided where boom-bust cycles are simultaneously consistent with stable inflation, as has been observed in the last decades in many economies.

Finally, it is examined whether the main assumption of the paper, explicit gains from trade due to the fact that workers are not perfectly mobile across all sectors of the economy in the short run, is supported by the data. Various panel estimations based on PSID data support the assumption. 


\section{Das Wichtigste in Kürze}

Konjunkturzyklen bilden Veränderungen im Handelsvolumen zwischen Individuen über die Zeit ab. In diesem Papier zeigen wir, dass das explizite Einbeziehen von intratemporalen Gewinnen aus dem Handel zwischen Individuen in ein makroökonomisches Model zum einen neue Einblicke in mögliche Mechanismen, welche konjunkturelle Schwankungen beeinflussen, eröffnen können. Zum anderen können sie dadurch zentrale wirtschaftspolitische Folgerungen verändern. Zunächst zeigen wir, wie ein „gains from trade“-Ansatz einfach erklären kann, warum Veränderungen in den Erwartungen (einschließlich „Nachrichten“ über die Zukunft und Risikoschocks) Auf- und Abschwünge auslösen können. Als nächstes wenden wir uns der Fiskalpolitik zu und erörtern, unter welchen Bedingungen Fiskalmultiplikatoren beobachtet werden können. Während ein Großteil unserer Analyse in einem Umfeld mit flexiblen Preisen erfolgt, präsentieren wir auch Implikationen unseres Modells mit Preisstarrheit. Dieses erlaubt, Auf- und Abschwünge bei stabiler Inflation zu verstehen. Die Quelle der expliziten Handelsgewinne in unserem Modellrahmen leitet sich von der einfachen Annahme ab, dass in der kurzen Frist Arbeiter nicht über alle Wirtschaftssektoren vollständig mobil sind. Wir präsentieren anhand Daten des PSID Fakten, die diese Modellannahme unterstützen, vor. 


\title{
A Gains from Trade Perspective on Macroeconomic Fluctuations
}

\author{
Paul Beaudry* and Franck Portier ${ }^{\ddagger}$ \\ This version: October 2011
}

\begin{abstract}
Business cycles reflect changes over time in the amount of trade between individuals. In this paper we show that incorporating explicitly intra-temporal gains from trade between individuals into a macroeconomic model can provide new insight into the potential mechanisms driving economic fluctuations as well as modify key policy implications. We first show how a "gains from trade" approach can easily explain why changes in perceptions about the future (including "news" about the future and risk shocks) can cause booms and bust. We then turn to fiscal policy, and discuss under what conditions fiscal multipliers can be observed. While much of our analysis is conducted in a flexible price environment, we also present implications of our model for a sticky price environments, as it allows to understand stable-inflation boom-bust cycles. The source of the explicit gains from trade in our setup derives from simply assuming that in the short run workers are not perfect mobile across all sectors of the economy. We provide evidence from the PSID in support of this modeling assumption.
\end{abstract}

Key Words: Business Cycle, Investment, Heterogeneous Agents

JEL Class.: E32

\footnotetext{
*Department of Economics, University of British Columbia and NBER.

†Toulouse School of Economics and CEPR

†The authors thank Florin Bilbiie, Russ Cooper, Wouter Den Hann and Henry Siu for discussions as well as participants in the various seminars where this work was presented. The authors would also like to thank Matias Cortes and Dana Galizia for research assistance. This paper is the result of a project sponsored within the scope of the SEEK research program which was carried out in cooperation with the Zentrum für Europäische Wirtschaftsforschung Gmbh (ZEW), Mannheim, Germany
} 


\section{Introduction}

Changes in measured macroeconomic activity are mainly driven by changes in the volume of trade between individuals. There are two types of causes for such changes. On the one hand, it may be that agents' capacity to exploit existing gains from trade changes over time due to changes in the importance of frictions or policy interventions. On the other hand, it may be that the actual scope in gains from trade between individuals changes. It would therefore seem natural that macro-economic models have at their core agents which gain from trading with each other in goods markets. However, many modern macro-models do not have such a feature as they either adopt a representative agent setup or introduce heterogeneity among individuals that leads only to trades in assets, not intra-temporal trade in goods. The aim of this paper is to illustrate how an explicit treatment of intra-temporal gains from trade in a macro setting provides new insights regarding the mechanisms behind fluctuations and the effects of policy. The main assumption we introduce in the model to generate trade among individuals is the notion that not all agents are perfect substitutes in the production of goods from different sectors.

Using a very simple framework which emphasizes gains from trade between individuals in investment good sectors versus those in consumption good sectors, we begin by showing how and under what condition changes in the perceived future returns on capital goods can lead to a simultaneous expansion of both the consumption good and investment good sectors. In our framework we do not need to take a stance on whether the perceived changes in future returns to capital are driven by objective news about future fundamentals (in the spirit of the "News shock" literature) or whether the perception changes are driven simply by error or a fad. While there are alternative setups that can also explain the type of expectation driven fluctuations we focus upon, we will show that the mechanism emphasized here is very intuitive and has solid empirical foundation. In particular, the mechanism that drives an expansion in our setup resembles a textbook type multiplier argument whereby the consumption by one agent of another agent's goods leads to subsequent demand effects that expand overall production. For example, if it is perceived that office buildings will be in high demand in the future, this creates gains from trade between those capable of producing office buildings and the rest of the agents in the economy. Agents in the rest of the economy will want to buy-either directly or indirectly-office buildings, and the builders of offices will accept to build more in exchange for goods produced by others. We show that such a process naturally leads to a generalized expansion when perceptions are optimistic, and if the perceptions are reversed, this should lead to a bust. We also show how this multiplier logic does not rely on sticky prices or departures from the permanent income hypothesis, but instead relies simply on sectoral labor markets that are not fully integrated in the short run. In our framework, the set of mutually desirable trades between individuals change solely due to changes in perceptions about the future value of certain goods. This contrasts with the RBC literature and many of its spin-offs, in which surprise improvements in technology directly change the gains from trade. ${ }^{1}$

In addition to examining the possibility of perception (or expectation) driven business cycles, we also show how our framework gives insight into the effects of government spending. To this end we use our framework to examine the effects of a temporary balanced budget increase

\footnotetext{
${ }^{1}$ In the RBC literature the notion of variation in the gains from trade between individuals is often not made explicit due to the representative agent setup, but the setup can easily be reinterpreted to capture this notion.
} 
in government spending. If labor markets are fully integrated, then it can be shown quite generally that temporary changes in government spending cannot lead to an increase in private consumption nor a multiplier greater than one in an equilibrium setting. However, if workers are not perfectly mobile across sectors, then depending on the nature of the tax-spending policy, we show that it can give rise to an increase in private consumption and possibly a multiplier greater than one. The main issue regarding whether government spending has a multiplier smaller or greater than one depends in our framework on whether the fiscal package increases substantially or not gains from trade between the individuals in the different sectors. ${ }^{2}$ A salient feature of our analysis is to show how labor market segmentation can simultaneously help explain both perception driven business cycles and the occasional expansionary effect of government expenditures.

While most of our analysis focuses on environments where prices are fully flexible, we also discuss implications of our gains from trade framework for monetary policy in a sticky price environment. To examine this issue we extend a quite standard new Keynesian macro-model to an environment with two sectors where agents are not mobile between sectors. In this environment we can derive the level of output that is consistent with stable prices. This level is often referred to as the natural rate. In basic New Keynesian models, changes in the natural rate are driven by either changes in productivity, changes in preferences or changes in labor market frictions. In contrast, in our set up changes in the natural rate can be driven simply by changes in perception about the future. ${ }^{3}$ Accordingly, in our framework a wave of optimism (defined as perception of high future return to capital) which creates more demand will simultaneously increase the natural rate. What looks like a demand shock -here a wave of demand for capital goods driven by the perception of high future returns - will not directly put upward pressure on prices, as in our model the natural rate increases in response to such a shock as it affects the gains from trade. Such a framework therefore easily explains why optimism-led expansions are not necessarily inflationary, and why pessimism driven busts may put very little downward pressure on inflation even when employment is very low.

The remaining sections of the paper are structured as follows. In section 2 we present our basic framework and derive the competitive equilibrium of the economy. In section 3, we show how and when changes in perceptions about the future can cause business cycle type fluctuations if agents are not perfectly mobile across sectors. As we use an extremely simple framework, we also discuss the generality of the results. In section 4 we discuss positive policy implications. We begin by exploring how changes in government spending can affect aggregate output in our framework. We show that under the same conditions which give rise to the possibility of perception driven business cycles, we also find that government spending can cause generalized booms even if the spending is limited to one sector of the economy. We also examine the implications of our framework for monetary policy in a sticky price setting. The main aspect we emphasize here is that the concept of a natural rate should not be viewed as primarily determined by productive capacity, frictions and preferences, and independent of what may appear as demand shocks. Instead we show that in our framework the natural rate

\footnotetext{
${ }^{2}$ If workers are fully mobile between sectors, wasteful government spending cannot create such gains from trade and therefore cannot have a multiplier effect. Therefore, our framework gives a reason why government expenditures may be used in the short run to stimulate economy activity while such effort would be unproductive in the long run, as workers are expected to be mobile in the long run.

${ }^{3}$ It is also the case that monetary policy shocks can change the natural rate in our framework.
} 
is inherently linked to changes in demand type shocks, and therefore even in such a simple model one cannot view changes in demand as inducing movement along a stable Phillips curve. The Phillips curve itself will change with demand shocks. Hence in our setup it is not the case that a supply shock renders a different type of inflation-output trade-off than that associated with a demand shock. Finally, in section 5, we discuss some normative issues and explore the relevance of our main assumption regarding labor market segmentation using PSID data over the period 1968-2007.

Note that throughout our analysis, our aim is to present the main ideas in the simplest possible setting. The results presented here are therefore all of a qualitative nature, and we present examples that can be solved analytically as much as possible. Given our focus on clarifying the qualitative implications for limited labor mobility, we leave for further exploration the quantitative implications of our framework.

\section{A simple framework for exploring the relationship be- tween gains from trade and macroeconomic outcomes}

\section{$2.1 \quad$ Fundamentals}

Let us begin by focusing on the simplest of cases in which we can explicitly model gains from trade : a two sector model, with two types of agents, one current period and a continuation value for the investment good. ${ }^{4}$ One sector produces consumptions goods, and the second sector produces investment goods, that is, goods that do not provide immediate utility. The two types of agents are denoted by $i=1,2$, where there is a mass $n^{i}$ of agents of type $i$. In period 1, an agent $i$ will have choices in terms of how much of the consumption good to purchase, $C^{i}$, how much of the investment good to purchase, $K^{i}$, and how much labor to supply, $L^{i}$. The production functions for consumption and investment goods satisfy constant returns to scale and depend on the amount hired of each type of labor, $i=1,2$. If the labor from the different types of worker enter additively in the production function, we will refer to this as a homogeneous labor market. If only one type of labor enters productively into the production of a good, we will refer to this as a situation with specialized labor markets. The function $F^{C}\left(L^{C 1}, L^{C 2}\right)$ will represent the amount of consumption produced when the amount $L^{C i}$ of type $i$ labor is employed in the consumption good sector. Similarly $F^{K}\left(L^{K 1}, L^{K 2}\right)$ will represent the production function in the investment sector. These production functions are assumed to be concave and satisfy constant returns to scale. ${ }^{5}$

The preferences of agent $i$ over consumption and labor in the current period are given by the utility function $U^{i}\left(C^{i}, 1-L^{i}\right)$, where $U(\cdot, \cdot)$ is concave, with both consumption $\left(C^{i}\right)$ and leisure $\left(1-L^{i}\right)$ being normal goods. This implies that $U_{1}>0, U_{2}>0, U_{22}-U_{12} \frac{U_{2}}{U_{1}}<0$ and

\footnotetext{
${ }^{4}$ This framework embeds fully specified dynamic models, as we will show by means of example

${ }^{5}$ For simplicity, we are assuming here that agents are not initially endowed with capital. Therefore only labor serves as an input in the current period. The results of this section can be easily extended to the case where agents are initially endowed with capital and capital enter as a factor of production in the production of capital goods and/or investment goods. In particular, Propositions 1 and 2 continue to hold in this modified setting. The only difference is for Proposition 3 which would need to be extended to include a restriction on the effects of capital mobility between sectors.
} 
$-U_{21}+U_{11} \frac{U_{2}}{U_{1}}<0 .^{6}$

Let us denote by $\widetilde{V}^{i}\left(K^{i} ; S\right)$ the value function of agent $i$ who enters next period in state $S$ with $K^{i}$ units of capital. The state vector $S$ that is relevant for the individual can be seen as composed of predetermined endogenous variables and of exogenous driving forces. The predetermined variables entering $\widetilde{V}$ could be the aggregate values of the capital stocks for each type of worker $\left(n^{1} K^{1}\right.$ and $\left.n^{2} K^{2}\right)$, while the exogenous random variables affecting the system could include the aggregate technology realization. ${ }^{7}$ In the current period, the agent will be assumed to have information that he perceives as relevant for predicting $S$, and this information will be denoted $\Omega$. This information could be individual specific, but for our purpose we will assume that it represents common information. The objective of the agent can then be expressed as maximizing

$$
U^{i}\left(C^{i}, 1-L^{i}\right)+E\left[\beta \widetilde{V}^{i}\left(K^{i} ; S\right) / \Omega\right],
$$

where $E[\cdot / \Omega]$ is the conditional expectation operator based on information $\Omega$, and $\beta$ is the discount factor. Note that $\Omega$ may content $S$.

To simply notation it is useful to define the expected continuation value function $V^{i}(\cdot)$ for agent $i$ as

$$
V^{i}\left(K^{i} ; \Omega\right)=E\left[\beta \widetilde{V}^{i}\left(K^{i} ; S\right) / \Omega\right] .
$$

We will refer to $V^{i}(\cdot)$ simply as the agent's value function.

\subsection{Modeling changes in expectations}

The important aspect to note about $V^{i}(\cdot)$ is its dependence on the information $\Omega$. In particular, we will be interested in knowing under what conditions changes in the exogenous components of $\Omega$ can cause business cycle type fluctuations, that is, we are interested in knowing when changes in the information set that agents perceive as being relevant for predicting the future may cause booms or busts ${ }^{8}$. We purposely choose to specify future preferences simply in terms of a continuation function as this will allow us to disregard all sorts of issues related to future adjustment of individuals. For example, even if we will sometimes assume that an individual's labor is specific to a sector, we are not assuming that this cannot be modified in the future. As we do not need to take a precise stand on how such issues play out in the future, and we want to highlight our results as easily as possible, the specification in terms of a continuation functions is very useful and without much loss of generality. For now all that we require about $V^{i}\left(K^{i} ; \Omega\right)$ is that it be continuous, differentiable, with $\frac{\partial V^{i}\left(K^{i} ; \Omega\right)}{\partial K^{i}} \geq 0$, and $\frac{\partial^{2} V^{i}\left(K^{i} ; \Omega\right)}{\partial K^{i}} \leq 0$.

It will be helpful to divide $\Omega$ into two sets. First we will denote by $\Omega_{1}$ information variables which are exogenous to the system, but which individuals consider relevant for predicting future state variables. For simplicity, we will treat $\Omega_{1}$ as a scalar. $\Omega_{1}$ could represent a current signal that agents receive regarding the future realization of exogenous driving forces impinging on

\footnotetext{
6 Subscripts on functions represent partial derivatives.

7 There may also be a third type of variable that enters $S$ which are economy wide endogenous variables such as prices. However, since such variables are themselves in equilibrium functions of the predetermined variables and the driving forces, there is no loss of generality in not including them in our specification of $\widetilde{V}(\cdot)$.

8 Depending on the context, a change in the exogenous components of $\Omega$ can be a change in the conditional expectation of $S$ when agents are learning or receiving news, but can also correspond to a change in some higher moments of the distribution of $S$, for instance a change in the (perceived) variance of $S$.
} 
the system, or alternatively $\Omega_{1}$ could simply represent a perception (sentiment) that agents share. $\Omega_{2}$ represents a set of endogenous variables that agents may want to use to predict future states, such as past prices or other past market outcomes.

\subsection{Competitive equilibrium}

The decision problem for individual $i$ can be expressed as

$$
\max _{C^{i}, K^{i}, L^{i}} U^{i}\left(C^{i}, 1-L^{i}\right)+V^{i}\left(K^{i} ; \Omega\right)
$$

subject to

$$
C^{i}+p K^{i}=w^{i} L^{i}
$$

where the agent takes prices and wages as given, $w^{i}$ represents the wage paid to agents of type $i$, and the consumption good is the numeraire. The problem for the consumption good firm is

$$
\max C-\sum_{i} w^{i} L^{C i}
$$

subject to

$$
C=F^{C}\left(L^{C 1}, L^{C 2}\right) .
$$

The problem for investment good firms is

$$
\max P K-\sum_{i} w^{i} l^{K 1}
$$

subject to

$$
K=F^{K}\left(L^{K 1}, L^{K 2}\right) .
$$

In this environment, a Walrasian equilibrium will need to satisfy, ${ }^{9}$ for $i=1,2$

$$
\begin{aligned}
\frac{U_{2}^{i}\left(C^{i}, 1-L^{i}\right)}{U_{1}^{i}\left(C^{i}, 1-L^{i}\right)} & =w^{i}, \\
\frac{V_{1}^{i}\left(K^{i} ; \Omega\right)}{U_{1}^{i}\left(C^{i}, 1-L^{i}\right)} & =p, \\
C^{i}+p K^{i} & =w^{i} L^{i}, \\
F_{i}^{C}\left(n^{1} L^{C 1}, n^{2} L^{C 2}\right) & =w^{i}, \\
P F_{i}^{K}\left(n^{1} L^{K 1}, n^{2} L^{K 2}\right) & =w^{i}, \\
L^{i} & =L^{C i}+L^{K i}, \\
n^{1} C^{1}+n^{2} C_{2} & =F^{C}\left(n^{1} L^{C 1}, n^{2} L^{C 2}\right), \\
n^{1} K^{1}+n^{2} K^{2} & =F^{K}\left(n^{1} L^{K 1}, n^{2} L^{K 2}\right) .
\end{aligned}
$$

\footnotetext{
${ }^{9}$ By Walras' Law, one condition here is redundant.
} 


\section{Expectation driven fluctuations}

\subsection{Definitions}

We are interested in examining whether, and under what conditions, changes in $\Omega_{1}$ (the exogenous component in the agents' information set) can cause positive co-movements between consumption, investment and employment. For this purpose, we define a positive change in $\Omega_{1}$ such that it corresponds to an increase in the perceived marginal (private) return to capital, that is, $\frac{\partial^{2} V^{i}\left(K^{i} ; \Omega\right)}{\partial K^{1} \partial \Omega_{1}}>0$. We will be interested in isolating conditions under which an increase in agents' perception of the marginal return to capital - that is, an increase in $\Omega_{1}$ - can cause a generalized boom, and when a decrease can cause a bust. ${ }^{10}$ Since the notion of a generalized boom and bust can have different meanings in a heterogeneous agent economy, we define the following terms:

Definition 1 The economy exhibits positive co-movement when aggregate consumption, aggregate investment, and employment of each type of worker all strictly increase together, or strictly decrease together.

Definition 2 The economy exhibits (strong) individual positive co-movement if the individual levels of consumption, investment and hours worked for each agent move weakly (strictly) in the same direction.

Definition 3 The economy exhibits positive price and quantity co-movement when wages and the price of capital move weakly in the same direction as aggregate consumption, investment and employment.

It should be clear that strong individual positive co-movement implies individual positive co-movement, which in turn implies positive co-movement. The only difference between strong individual positive co-movement and individual positive co-movement is that in the latter case some individual level variables are allowed to remain unchanged. Equipped with these definitions we can now explore under what conditions changes in perception regarding the marginal value of capital, represented by changes in $\Omega_{1}$, can cause positive co-movement.

When looking at how changes in perceptions may affect the economy, it is unclear what concepts defined above one may want the economy to satisfy to be considered most empirically interesting. Positive co-movement between investment, consumption and employment is one of the central established features of business cycles, so it is certainly desirable that it is satisfied. Since our framework allows for two types of workers, and since we do not believe that negative correlation between the employment of different types of workers is a key feature of business cycles, we will focus mainly on situations that satisfy our definition of positive co-movement. Nonetheless, since we also know of no evidence suggesting that the main positive co-movements in aggregate consumption and investment hide substantial heterogeneity in the sign of the response at the individual level, we believe that it is also interesting to know whether a model can produce positive co-movement by relying only on individual level positive co-movement. Whether the individual level outcomes for consumption and investment should move strongly

\footnotetext{
${ }^{10}$ Answering this question simply requires doing a comparative static exercise on the above set of equilibrium equations.
} 
or weakly with the aggregates appears to us as being of minor importance. With respect to positive price and quantity co-movement, the desirability of this feature may depend on what type of capital one may be considering. We believe that positive price-quantity co-movement is a potentially desirable feature as real wages are generally viewed as pro-cyclical; and the price of capital- which we view as representing either the price of real-estate or value of capital represented by the stock market- is also seen as being pro-cyclical. However, if one views the price of capital as the price of equipment it is unclear whether one would want changes in perception to increase or decrease such a price.

\subsection{Three propositions}

Our first proposition is meant to illustrate that the Walrasian framework is not very restrictive in terms of it capacity to generate interesting co-movements in response to changes in perceptions. In effect, it only places quite mild restrictions in the sense that it cannot generate strong individual positive co-movement.

Proposition 1 The Walrasian equilibrium of our economy can simultaneously exhibit individual positive co-movement and positive price-quantity co-movement in response to a change in $\Omega_{1}$, but it cannot exhibit strong individual co-movement.

To illustrate the first part of this proposition, we provide the following example. The proof of the second part of the proposition is given in the appendix. In this example the function $V(\cdot)$ is taken as data. Later in this section we will provide examples where $V(\cdot)$ can be derived from more primitive assumptions.

Example : Preferences for producer of type 1 agent are given by

$$
\begin{aligned}
U^{1}\left(C_{1}, L^{1}\right) & =\ln \left(C_{1}\right)+\nu\left(1-L^{1}\right), \\
V^{1}\left(K^{1}, \Omega_{1}\right) & =\phi \Omega_{1} \ln \left(K^{1}\right),
\end{aligned}
$$

and preferences of type 2 are

$$
\begin{aligned}
U^{2}\left(C^{2}, L^{2}\right) & =\ln \left(C^{2}-a L^{2}\right), \\
V^{2}\left(K^{2}, \Omega_{1}\right) & =\psi \Omega_{1} \ln \left(K^{2}\right) .
\end{aligned}
$$

The production function for consumption goods is $C=L^{1}$; that is only type 1 can produce consumption goods. The production of investment goods is $K=L^{2}$; that is only type 2 can produce investment goods. There is a mass one half of each type of individual.

The solution for this example is

$$
\begin{aligned}
L^{2} & =\sqrt{\left.\frac{2 \Omega_{1} \phi\left(1+\psi \Omega_{1}\right)}{a \nu\left(2+\Omega_{1} \psi\right)}\right)}, & L^{1} & =\frac{1}{\nu}+\frac{\Omega_{1} \phi}{\nu}, \\
P & =a L^{2}, & I_{2} & =\frac{P \Omega_{1} \psi}{\left(1+\Omega_{1} \psi\right) 2 a} \\
I_{1} & =\frac{P\left(2+\psi \Omega_{1}\right)}{2 a\left(1+\psi \Omega_{1}\right)}, & C_{2} & =P I_{1}, \\
C^{1} & =\frac{1}{\nu}, & &
\end{aligned}
$$


As can be seen, all these quantities increase with an increase in $\Omega_{1}$ except for $C^{1}$, which is independent of $\Omega_{1}$. Hence in this example an increase in $\Omega_{1}$ leads to individual positive co-movement. Moreover, both the price of capital and the average wage (in consumption units) increase and therefore it also exhibits positive price-quantity co-movement. The intuition for this result is the following: an increase in $\Omega_{1}$ increases the demand for capital. This increase in demand increases the price of the investment good. As the utility function of the capital good workers shows zero wealth effect in labor supply, they will respond by producing more capital, accepting more consumption in exchange. As consumption of the consumption good worker is constant, consumption production needs to increase with investment production. Therefore, employment in the two sectors also increase.

Note that the only restriction being imposed by Proposition 1 on the Walrasian equilibrium is that not all current decision variables of individuals can strictly increase in response to a perceived change in the marginal value of capital. At least one variable for one individual must stay the same or decrease. ${ }^{11}$ This restriction may appear very minor, which we believe is the right interpretation. However, it should be noted that in the case where we impose a representative agent structure, it implies the stronger result that aggregate positive co-movement is not possible.

Corollary 1 If we have a representative agent, in the sense that the preferences of agents 1 and 2 are identical and their labor is perfectly homogeneous, then the Walrasian equilibrium of the economy cannot exhibit positive aggregate co-movement in response to a change in $\Omega_{1}$.

Corollary 1 echoes the well known result of Barro and King [1984] whereby demand disturbances were shown not to be able to generate positive co-movement between consumption and employment in a representative agent setup. In Barro and King [1984], the result was stated in a one sector model, and can seen very easily by examining the labor market equilibrium condition:

$$
\frac{U_{2}(C, 1-L)}{U_{1}(C, 1-L)}=F_{1}(L)
$$

Under the condition that $F_{11} \leq 0$ and both consumption and leisure are normal, then it follows from total differentiation of that equation that consumption and labor must move in opposite directions when responding to changes in perceptions. Corollary 1 simply provides an extension to the two sector model. ${ }^{12}$

Proposition 1 and Corollary 1 suggest that if one is interested in understanding perception driven business cycles, remaining in a Walrasian equilibrium framework may be promising but in such a case it is necessary to drop the representative agent structure. However, what this proposition does not tell us is what aspect of the representative agent framework should be dropped: is it the identical preferences or the differences in labor. Proposition 2 addresses this issue.

\footnotetext{
${ }^{11}$ While Proposition 1 indicates that individual positive co-movement induced by a change in perception can arise in a Walrasian setting, it is worth noting that such an outcome- where there is no decrease in any of the individual outcomes - arises only when there is constant dis-utility of work. In contrast, aggregate positive co-movement induced by perception does not rely on such a linearity assumption.

${ }^{12}$ See also Beaudry and Portier [2007] for a related discussion.
} 
Proposition 2 If labor is homogeneous, the Walrasian equilibrium of our economy cannot exhibit positive co-movement in response to a change in $\Omega_{1}$. In contrast, if preferences are identical but labor markets are specialized, then the Walrasian equilibrium of our economy can exhibit positive co-movement, positive individual co-movement and positive price-quantity comovement.

Proposition 2 indicates that short run labor market segmentation may be a key feature for understanding certain aspects of business cycle phenomena. In particular the proposition highlights that it is not preference heterogeneity that is essential for generating perception driven positive co-movement in our Walrasian setting but instead it is the notion that not all agents are equally valuable at producing all goods in the short run. When agents are specialized in the goods they can produce in the short run, this creates a situation where there are explicit gains from trade between individuals. Accordingly, we interpret Proposition 2 as indicating why it may be relevant to build macroeconomic models where there are explicit gains from trade in the goods markets between individuals. The reason why labor market specialization can support perception driven booms and busts is that the change in perception changes the desirable trades between individuals. For example, when returns to capital accumulation appear high, agents in the consumption sector want to trade with workers in the investment sector. Such gains from trade therefore favor a simultaneous increase in the production of both consumption and investment goods.

Propositions 1 and 2 indicate that perception driven positive co-movement is possible in our simple Walrasian framework, but they do not indicate whether such outcomes can arise in reasonable setups, or whether they require strong additional assumptions. Accordingly, our aim now is to derive a set of sufficient conditions for the economy to exhibit positive aggregate comovement in response to an increase in $\Omega_{1}$. To this end, as suggested by Proposition 2, we will assume that agents are specialized in production in the short run, that is, we will assume that agents of type 1 can only produce the consumption good in the short run, while agent of type 2 can only produce the investment good, and we look for sufficient conditions whereby changes in perceptions can cause positive co-movement. As these production functions have constant returns to scale, there is no loss of generality to assuming that one unit of labor produces one unit of output in each sector.

The sufficient conditions for perception driven positive co-movement can be stated in terms of the primitives $U^{i}(\cdot)$ and $V^{i}(\cdot)$. However, this results in very unintuitive expressions. For this reason, we will instead proceed by presenting sufficient conditions in terms of demand and supply functions. In particular, let us define the capital demand function, $K^{i}\left(p, w^{i} ; \Omega\right)$, the consumption demand function, $C^{i}\left(p, w^{i} ; \Omega\right)$, and the labor supply function of agent $i, L^{i}\left(p, w^{i} ; \Omega\right)$, as the functions that solve the optimization problem

$$
\max _{C^{i}, K^{i}, L^{i}} U\left(C^{i}, 1-L^{i}\right)+V^{i}\left(K^{i} ; \Omega\right)
$$

subject to

$$
C^{i}+p K^{i}=w^{i} L^{i}
$$

Sufficient conditions for an increase in $\Omega_{1}$ to induce positive aggregate co-movement are given in Proposition 3. 
Proposition 3 If workers are specialized across sectors in the short run, and if the continuation value for each agent is of the form $V^{i}\left(K^{i} ; \Omega_{1}\right)$, with $V_{12}^{i}>0$, then an increase in $\Omega_{1}$ will be associated with positive aggregate co-movement (and positive quantity and price co-movement) if

(i) an increase in $w^{2}$ does not decrease the labor supply of type 2, that is, $\frac{\partial L^{2}}{\partial w^{2}} \geq 0$,

(ii) an increase in the price of capital does not decrease labor supply of either type of agent, that is, $\frac{\partial L^{i}}{\partial p} \geq 0$ for $i=1,2$.

(iii) An increase in the price of capital leads to a decrease in aggregate capital demand when including the income effect induced on type 2 agents, that is, $\frac{\partial K^{1}}{\partial p}+\frac{\partial K^{2}}{\partial p}+\frac{\partial K^{2}}{\partial w^{2}}<0$.

Proposition 3 highlights a set of conditions which together are sufficient to support perception driven aggregate co-movements. Let us emphasize that substantially weaker conditions can be found but they are not very elegant to state. For example, the effect of an increase in the price of capital on labor supply can be negative, as long as it is not too negative. Similarly, the proposition is stated for the case where agents only use exogenous information $\Omega_{1}$ to predict future states $\left(\Omega_{2}\right.$ is either empty or does not affect the marginal return to capital). This again is much stronger than needed to get positive co-movement, but it greatly simplifies the proposition.

The main conditions in Proposition 3 are easy to interpret. The first condition simply states that the labor supply of agents in the capital goods sector must respond non-negatively to an increase in their wage, that is, it must be that the substitution effect of an increase in wages dominates the income effect in this sector. As a change in wages here corresponds to a change holding all future variables constant (including expected future wages as predicted by $\Omega_{1}$ ), this condition appears very reasonable. It is quite obvious why such a condition will need to hold. If an increase in the perceived return to capital is to cause a boom, it will need to work though an increase in employment of capital sector workers. Such an increase in unlikely to materialize unless an increased demand for workers in this sector leads to increased employment.

More generally, to understand the role of the three conditions in Proposition 3 it is helpful to notice that the model equilibrium conditions can be reduced to an equilibrium condition in the capital goods sector. Using the constant returns to scale assumption, and the fact that the firm's first order conditions imply - given the simple one-to-one production technology that $w^{2}=p$ and $w^{1}=1$ (where 1 is the price of the consumption good), we can write the equilibrium condition in the capital sector as:

$$
K^{1}\left(p, 1 ; \Omega_{1}\right)+K^{2}\left(p, p ; \Omega_{1}\right)=L^{2}\left(p, p ; \Omega_{1}\right) .
$$

The left side of this equation is the aggregate capital demand curve, and the right side is the aggregate capital supply curve. Conditions (i) and (ii) in Proposition 3 guarantee that the capital supply function is (weakly) upward sloping, and condition (iii) guarantees that the demand is downward sloping, as illustrated in Figure 1.

In other words, these conditions imply that this market is of the textbook type. Hence, Proposition 3 can be interpreted as indicating that perceptions driven aggregate co-movement will arise if the market for capital is well behaved and the labor market is segmented in the short run. The reason why we obtain positive co-movement in consumption and investment in this setup derives directly from the intra-temporal gains from trade induced by the labor market segmentation. When $\Omega_{1}$ increases, consumption sector agents want to buy capital from 
Figure 1: Illustration of the Sufficient Conditions of Proposition 3

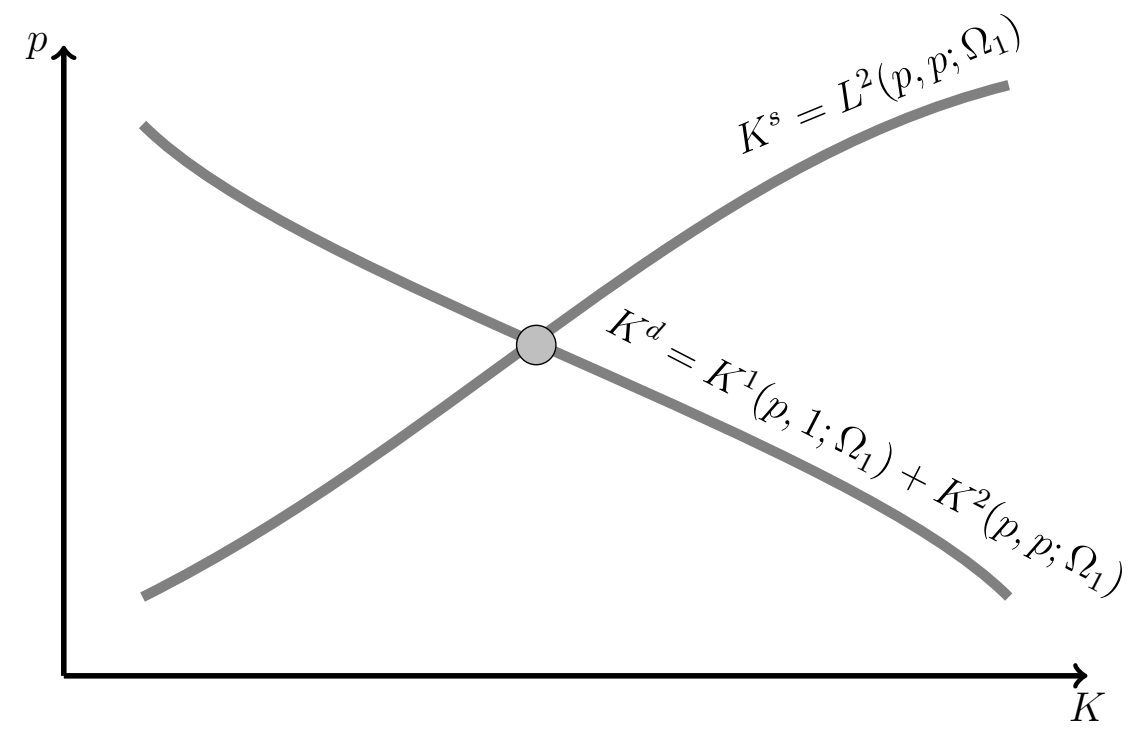

This economy satisfies the sufficient conditions of Proposition 3: aggregate capital supply is (weakly) upward sloping and aggregate capital demand is downward sloping.

workers in the capital goods sector. With an upward sloping labor supply curve, the capital goods sector workers will respond to this new demand by favoring a greater trade flow between the two types of workers, which corresponds to an increase in economic activity. It could be the case that both types of agents reduce their purchase of their own good to offset these increased interpersonal transactions, but under the conditions of Proposition 3 this won't happen. This is why positive perceptions about the future can cause a generalized boom in the presence of explicit gains from trade, while such positive co-movement would not be possible - as noted in Proposition 2 - if labor markets were homogeneous.

We could at this point try to provide sufficient conditions for an increase in $\Omega_{1}$ to be associated with individual positive co-movement. Although it is rather easy to build examples where this property is satisfied, we have not found any very insightful sufficient conditions, ${ }^{13}$ and accordingly we have not chosen to pursue this issue further. ${ }^{14}$

\footnotetext{
${ }^{13}$ For example, if we want capital purchases for type 1 individuals to respond positively to an increase in $\Omega_{1}$, we need

$$
-\frac{\partial K^{1}\left(P, 1 ; \Omega_{1}\right)}{\partial P} \frac{d P}{d \Omega_{1}}<\frac{\partial K^{1}\left(P, 1 ; \Omega_{1}\right)}{\partial \Omega_{1}},
$$

where $\frac{d P}{d \Omega_{1}}$ is implicitly defined by the total derivative of $P$ with respect to $\Omega_{1}$.

${ }^{14}$ It should be noted that individual positive co-movement requires quite restrictive assumptions. For example it generally requires, among others, that leisure enter linearly in the utility of the consumption sector workers and that there be no decreasing returns to labor in the production of consumption goods. Accordingly, we view individual positive co-movement as a rather knife edge possibility within a Walrasian framework.
} 


\subsection{Some explicit dynamic examples}

In this section we want to present two simple examples of economic environments where increases in the perceived return to capital or decreases in its perceived risk can cause a boom, while decreases in the perceived return or increases in perceived risk can cause a bust. We have chosen examples that can be solved explicitly, as to best illustrate our results. As is well known, it is difficult to get explicit solutions in dynamic general equilibrium models and accordingly we must resort to highly simplified environments. We begin by an overlapping generation model with complete depreciation, and complete sector specialization. Then we present an infinitely lived agent setup with incomplete depreciation. A special case of the second example will be later used to analyze monetary policy with sticky prices.

\section{Example 1 : An overlapping generation model with changes in risk perception}

Agents live for two periods, and have preferences given by

$$
\frac{\left(C_{t}^{y i}\right)^{1-\sigma}}{1-\sigma}+\nu\left(1-L_{t}^{i}\right)+E_{t} \frac{\left(C_{t+1}^{o i}\right)^{1-\sigma}}{1-\sigma}
$$

with $\sigma \geq 0$. In the first period of their life they can consume, supply labor and buy capital. $C_{t}^{y i}$ represents the consumption of agent $i$ when young at time $t$, and $C_{t}^{o i}$ represents the consumption of the old of period $t$. In the second period they can consume the returns from their capital. Capital is assumed to fully depreciate after one period. Agents of type 1 can only produce consumption goods while agents of type 2 can only produce capital goods. We will let $K_{t}^{i}$ represent the capital bought by agent $i$ at time t. Both labor and capital can be used to produce consumption goods according to the production function $C_{t}=A_{t} K_{t}+L_{t}^{1}$. $A_{t}$ is $i i d$, log-normally distributed with mean 1 and variance $v_{t}^{2}$. The production of the capital good is given by $K_{t+1}=L_{t}^{2}$. We assume that in period $t$ agents receive a perfect signal about $v_{t+1}^{2}$, that is, $\Omega_{1 t}=v_{t+1}^{2}$. The continuation value function for this example can be shown to be given by $V\left(K_{t+1}^{i}, \Omega_{1 t}\right)=\left(1+\Omega_{1 t}\right)^{-\frac{1}{2} \sigma(1-\sigma)} \frac{\left(K_{t+1}^{i}\right)^{1-\sigma}}{1-\sigma}$.

The solution to this example is $P_{t}=\left(1+\Omega_{1 t}\right)^{-\frac{\sigma}{2} \frac{1-\sigma}{2-\sigma}}, C_{t}^{y 1}=\nu^{-\frac{1}{\sigma}}, C_{t}^{y 2}=\left(\frac{1}{\nu}\right)^{\frac{1}{\sigma}}\left(1+\Omega_{1 t}\right)^{-\frac{1}{2} \frac{1-\sigma}{2-\sigma}}$, $C_{t}^{o}=A_{t} K_{t}, K_{t+1}^{1}=\nu^{-\frac{1}{\sigma}}\left(1+\Omega_{1 t}\right)^{-\frac{1}{2} \frac{(1-\sigma)^{2}}{2-\sigma}}$ and $K_{t+1}^{2}=\nu^{-\frac{1}{\sigma}}\left(1+\Omega_{1 t}\right)^{-\frac{(1-\sigma)}{2}}$

From this solution, it can be verified that an expected increase in risk $\Omega_{1 t}$ will lead to positive individual co-movement as long as $\sigma<1$. Note that $\sigma<1$ is sufficient here for wages to have a positive effect on labor supply and for an expected increase in $\Omega_{1 t}$ to cause a decrease in the perceived return to capital, and therefore a bust.

\section{Example 2: A model with infinitely lived agents}

Consider an environment where we have two infinitely lived agents. The labor of agents of type 1 is valuable only in the production of consumption goods and their preferences are given by

$$
\sum_{j=0}^{\infty} \beta^{j}\left(\ln C_{t+j}^{1}+\nu\left(1-L_{t+j}^{1}\right)\right) .
$$


The second type of agents can only produce investment goods and their preferences are given by

$$
\sum_{j=0}^{\infty} \beta^{j} \ln \left(C_{t+j}^{2}-\frac{\left(L_{t+j}^{2}\right)^{1+\gamma}}{1+\gamma}\right), \quad \gamma>0 .
$$

Capital depreciates at rate $\delta$ such that the aggregate capital stock satisfies $K_{t+1}=(1-\delta) K_{t}+I_{t}$, where the production of capital is given by $I_{t}=L_{2}^{2}$. The production of the consumption good is given by $C_{t}=A_{t} K_{t}+L_{t}^{1}$. Perfect substitutability between capital and labor allows for an analytical solution.

The return on capital, $A_{t}$, is assumed to be i.i.d., with mean zero and composed of two independent components: $A_{t}=\epsilon_{t}+s_{t-N}$. The $\epsilon_{t}$ component is assumed to be non-predictable, while the second component $s_{t-N}$ is a news, i.e. it is assumed to be known to agents $N$ periods before it actually affects returns. Therefore the set of exogenous information relevant for individuals when making predictions at time $i$ is $\Omega_{1 t}=\left\{s_{t}, \ldots, s_{t-N-1}\right\}$.

In this setup much of the equilibrium outcome can be solved analytically. In particular, the equilibrium will be characterized by the price of capital at time $t$ be given by

$$
P_{t}=\beta\left(\sum_{j=0}^{N-1}(\beta(1-\delta))^{N-1-j} s_{t-j}\right) .
$$

Investment and employment in the investment sector are given by

$$
I_{t}=L_{t}^{2}=\left(\beta \sum_{j=0}^{N-1}(\beta(1-\delta))^{N-1-j} s_{t-j}\right)^{\frac{1}{\gamma}} .
$$

Aggregate consumption and employment in the consumption sector are given by

$$
\begin{gathered}
C_{t}=\frac{1}{\nu}+\frac{\left(\beta \sum_{j=0}^{N-1}(\beta(1-\delta))^{N-1-j} s_{t-j}\right)^{\frac{1+\gamma}{\gamma}}}{1+\gamma}+\mu_{t}, \\
L_{t}^{1}=\frac{1}{\nu}+\frac{\left(\beta \sum_{j=0}^{N-1}(\beta(1-\delta))^{N-1-j} s_{t-j}\right)^{\frac{1+\gamma}{\gamma}}}{1+\gamma}+\mu_{t}-A_{t} K_{t}
\end{gathered}
$$

where $\mu_{t}$ is the marginal utility of consumption of type two agents. While we are not able to provide a explicit expression for $\mu_{t}$, it can be deduced that it is increasing with the signal $s_{t}$. From the above equations we can see how the elements in $\Omega_{1 t}$ affect consumption and investment. In particular, consider the dynamics induced when agents receive a positive realization of $s_{t}$, that is, agents at time $t$ receive a signal telling them that returns to capital will likely be high in $N$ periods. This immediately gives rise to an increase in investment, as the payoff to investment has increased. Moreover, it leads to an increase in aggregate consumption as the positive signal has increased the gains from trade between type 1 and type 2 agents. Positive co-movement therefore arises as investment increases and workers in the investment sector buy more consumption goods. Over time the effect of this signal builds up as the perceived higherthan-normal return to capital becomes more salient. Eventually, the period of high perceived 
return comes to an end - with or without the returns actually being confirmed - and then the economy enters a recession as investment falls back to normal and the economy liquidates its capital stock.

As the marginal utility term $\mu_{t}$ in the above equations cannot be solved explicitly, it is of interest to compare the solution with a case which can be entirely solved. This corresponds to the situation where the type 2 agents are myopic (meaning that they only make static consumption/leisure decisions). In this case, $P_{t}, I_{t}$ and $L_{t}^{2}$ all take the exact same form as given above. All that changes is $C_{t}$ and $L_{t}^{1}$, which are now given by

$$
\begin{gathered}
C_{t}=\frac{1}{\nu}+\left(\beta \sum_{j=0}^{N-1}(\beta(1-\delta))^{N-1-j} s_{t-j}\right)^{\frac{1+\gamma}{\gamma}}, \\
L_{t}^{1}=\frac{1}{\nu}+\left(\beta \sum_{j=0}^{N-1}(\beta(1-\delta))^{N-1-j} s_{t-j}\right)^{\frac{1+\gamma}{\gamma}}-A_{t} K_{t} .
\end{gathered}
$$

Here, when type 2 agents are myopic, the qualitative dynamics induced by increases in the perceived returns to capital are essentially the same as when type 2 agents optimize over time. For this reason, we believe that the case where type 2 agents are myopic provides a tractable example that can be used effectively to explore implications of specialized labor markets, knowing that the qualitative properties are very close to the case where type 2 agents optimize fully over time. In a later section we will use this extended example where type 2 agents are myopic to examine some implication of sticky prices.

\subsection{Allowing for contingent claims}

Our analysis may at first pass appear restrictive since it does not include financial claims that agents trade among themselves. In particular, one may want to allow agents to trade in a full set of state contingent claims markets, where the contingencies would be the different possible realizations of the random variables in $S$. However, after closer inspection, we can show that our analysis is not restrictive on this front, as such trades can be viewed as being subsumed in the functions $V^{i}(\cdot)$. To see this suppose, suppose that agents can trade in contingent claims markets and therefore can enter a period with a portfolio of contingent claims denoted $\left\{y_{n}^{i}\right\}_{n=1}^{N}$, where $N$ is the number of potential realization of $S$, and $y_{n}^{i}$ represents the number of claims to be paid in state $n$ held by agent $i$. The problem facing the agent would then correspond to

$$
\max _{C^{i}, L^{i},\left\{y_{n}^{i}\right\}_{n=1}^{N}} U\left(C^{i}, 1-L^{i}\right)+E\left[\beta \widetilde{V}^{i}\left(\left\{y_{n}^{i}\right\}_{n=1}^{N} ; S\right) / \Omega\right]
$$

subject to

$$
C^{i}+\sum_{n} p_{n} y_{n}^{i}=w^{i} L^{i}
$$

where $p_{n}$ are the prices of contingent claims and $\widetilde{V}^{i}\left(\left\{y_{n}^{i}\right\}_{n=1}^{N} ; S\right)$ represents the value of entering a period with the portfolio $\left\{y_{n}^{i}\right\}_{n=1}^{N}$ when the state is $S$. Now consider the following sequence 
of budget constraints

$$
\begin{aligned}
C^{i}+p K^{i} & =w^{i} L^{i} \\
\sum_{n} p_{n} y_{n}^{i} & =\sum_{n} p_{n} r_{n} K^{i}
\end{aligned}
$$

where $r_{n}$ are the returns on capital in the different states. In this sequence of budget constraints, an individual would first face a budget constraint where he decides how much capital to buy and then uses the capital to purchase continent claims. The important aspect to notice is that this sequence of budget constraints is actually equivalent to the budget constraint $C^{i}+\sum_{n} p_{n} y_{n}^{i}=$ $w^{i} L^{i}$ if $p K^{i}=\sum_{n} p_{n} r_{n} K^{i}$. But this last condition is assured by arbitrage. Hence, we can view the problem facing an agent in the contingent claims setup as one where the agent first chooses $C^{i}, K^{i}$ and $L^{i}$, and then chooses $\left\{y_{n}^{i}\right\}_{n=1}^{N}$. The problem facing the agent initially can therefore be rewritten as

$$
\max _{C^{i}, L^{i}, K^{i}} U\left(C^{i}, 1-L^{i}\right)+V\left(K^{i} ; \Omega,\left\{P_{n}\right\}_{n=1}^{N}\right)
$$

subject to

$$
C^{i}+p K^{i}=w^{i} L^{i}
$$

where $V\left(K^{i} ; \Omega,\left\{P_{n}\right\}_{n=1}^{N}\right)$ is now the value function associated with

$$
V\left(K^{i} ; \Omega,\left\{P_{n}\right\}_{n=1}^{N}\right)=\max _{\left\{y_{n}^{i}\right\}_{n=1}^{N}} E\left[\beta \widetilde{V}^{i}\left(\left\{y_{n}^{i}\right\}_{n=1}^{N} ; S_{1}, S_{2}\right) / \Omega, S_{1}\right]
$$

subject to

$$
\sum_{n} p_{n} y_{n}^{i}=\sum_{n} p_{n} r_{n} K^{i}
$$

Given this two step interpretation, the problem facing the agent when deciding $C^{i}, K^{i}$ and $L^{i}$ is now almost identical to what we had in the previous section with the exception that now the state contingent prices $\left\{P_{n}\right\}_{n=1}^{N}$ are added arguments in the value function. However, in equilibrium the state contingent prices themselves will be a function of $\Omega$ and therefore they can be replaced in the value function of the form $V\left(K^{i} ; \Omega,\left\{P_{n}\right\}_{n=1}^{N}\right)$, to give us back a value function of the form $V\left(K^{i} ; \Omega\right)$. Accordingly, our Propositions 1 to 3 can be seen as applying equally well to a situation where agents have access to contingent claims on the realizations of $S$ or when they do not. The difference between the two cases will affect the shape of the relevant value function, but that does not impinge on the propositions. Moreover, it is important to note that in this argument we have not placed any non-negativity constraint on $K$ as allowing for such a possibility is necessary for the equivalence result.

\subsection{Ex-ante markets on perceptions $\Omega_{1}$}

We have shown that perception driven booms and busts (e.g. based either on hard information, rumor or fad) can arise quite naturally in environments where there are explicit gains from trade between individuals because of short run labor market specialization. Moreover we have shown that perception driven fluctuations can arise even in situation where agents can share risk regarding the outcomes on which they make perceptions. However, we have not yet examined what would happen if we allowed people to insure themselves against changes in perceptions 
themselves. While we view the existence of a full set of such markets somewhat unlikely, in this section we will discuss how our analysis is modified if we allow agents to meet before the realization of $\Omega_{1}$ and trade contingent claims markets written on the realizations of the perceptions themselves. If we assume that $\Omega_{1}$ can take on $M$ values $(m=1, . ., M)$, and the probability of each of these outcomes is given by $\Pi_{m}$, then the problem facing agent $i$ in the case where ex-ante markets contingent on $\Omega_{1}$ are available is

$$
\max _{\left\{C_{m}^{i}\right\}_{m=1}^{M},\left\{K_{m}^{i}\right\}_{m=1}^{M},\left\{L_{m}^{i}\right\}_{m=1}^{M}} \sum_{m=1}^{M} \Pi_{m}\left[U^{i}\left(C_{m}^{i}, 1-L_{m}^{i}\right)+V^{i}\left(K_{m}^{i} ; \Omega_{1 m}, \Omega_{2}\right)\right]
$$

subject to

$$
\sum_{m=1}^{M} P_{m}^{c} C_{m}^{i}+\sum_{m=1}^{M} P_{m}^{I} K_{m}^{i}=\sum_{m=1}^{M} w_{m}^{i} L_{m}^{i}
$$

where, for example, $C_{m}^{i}$ is the claims of agent $i$ for consumptions goods when the realization of $\Omega_{1}$ is $\Omega_{1 m}$, and $P_{m}^{c}$ is the price of this contingent claim.

For this case, we have results which complement those in Propositions 1 to 3, that is,

Proposition 4 When agents are allowed to trade contingent claims written on the realization of $\Omega_{1}$, then positive co-movement is not possible if either labor is homogeneous or if labor specialized and the preferences $U(C, 1-L)$ are separable.

Proposition 4 indicates that in the presence of ex-ante claims on $\Omega_{1}$, it is much more difficult to generate positive co-movement driven by changes in perception even in the case where agents are specialized, as it requires that preferences be non-separable. Accordingly, we take Proposition 3 and 4 as indicating that positive co-movement driven by perception can arise quite easily when agents are specialized and they can't diversify all the risk associated with changes in perceptions about the future. However such positive co-movement is much less likely to arise if ex-ante markets for $\Omega_{1}$ exist. In particular, when agents are specialized and preferences are separable, the insurance provided by ex-ante markets written on $\Omega_{1}$ results in the consumption of both agents becoming independent of the realization of $\Omega_{1}$, and therefore positive co-movement is not possible.

\section{Positive policy analysis}

In section 3 we established that introducing explicit intra-temporal gains from trade between individuals (due to labor market segmentation) in a macroeconomic model offers an environment where changes in perceptions about the future can cause business fluctuations under seemingly reasonable conditions. In this section we want to explore whether such a framework also provides new insight into fiscal and monetary issues. We begin by exploring the link between labor market specialization and the effects of fiscal policy within a Walrasian framework. Then we will explore a sticky price model with explicit gains from trade which we present as a simple extension of the baseline New Keynesian model. 


\subsection{Fiscal policy}

\subsubsection{Introducing a government}

We continue to work here with the setup of Section 2 where we have two types of individuals who can differ in terms both of their preferences (represented by $U^{i}\left(C^{i}, 1-L^{i}\right)$ and $V^{i}\left(K^{i} ; \Omega\right)$ ) and in terms of value of their labor in the production of the two different goods. In this environment, we want to explore the effect of temporary changes in government spending. To keep the discussion as simple as possible, we choose to look at fiscal policies which are composed only of current government expenditures paid by current taxes. This clearly makes the policy temporary and will allow us to side step any issues related to future expectations of policy and of non-Ricardian equivalence. A fiscal policy will therefore be composed of current expenditure by the government in terms of consumption goods, $G^{C}$, an expenditure in terms of capital goods, $G^{K}$, a lump sum tax on type 1 individuals, $T^{1}$, and a lump sum tax on type 2 individuals, $T^{2}$. The balanced budget requirement imposes:

$$
G^{C}+p G^{K}=T^{1}+T^{2} .
$$

We will assume that type 1 is taxed a proportion $\alpha$ of total expenditure, that is $T^{1}=\alpha\left(G^{C}+\right.$ $G^{K}$ ), with the remaining fraction corresponding to the tax on type 2 individuals. A common question that arises about fiscal policy is whether and under what conditions (if any) can a temporary increase in government spending create a multiplier effect, in the sense that the total effect of a government spending increase of one dollar leads to an effect on aggregate output of more than one dollar. It is well known that in a Walrasian setting temporary increases in government spending generally lead to a multiplier that is less than one as the new expenditures tend to crowd out expenditures by households on either investment or consumption purchases. In this subsection we want to examine whether the introduction of explicit gains from trade between individuals changes such results. To present our results as clearly as possible, and to help shed new light on the issue, it is helpful to focus on government expenditures that are directed only at one sector. To this end, let us consider a fiscal policy which is directed at purchasing investment goods, where these goods are either wasted or enter separately into households' preferences.

To understand if a change in $G^{K}$ can have a multiplier greater than one it is helpful to first break down the question into two simpler elements: (i) can an increase in government purchases of capital goods cause private agents to buy more capital goods, if so we would call this an amplification effect, and (ii) can an increase in government purchases of capital goods cause private agents to consume more consumption goods, if so we would call this a spillover effect. The following propositions address these issues.

Proposition 5 If the preferences of agents are identical and their labor is perfectly substitutable (i.e. a representative agent setup), then an increase in government purchases of capital goods cannot lead to either an increase in private purchase of either capital goods (no amplification effect) or consumption goods (no spillover effect). Hence government purchases of investment goods cannot in this case create positive aggregate co-movement nor create a multiplier greater than one.

Proposition 5 echoes previous results regarding the crowding out effects of government 
spending in a Walrasian setting. ${ }^{15}$ As stated in the Proposition, when there is no explicit gains from trade between individuals (i.e. a representative agent setup), an increase in public spending tends to crowd-out private expenditures. In effect, in our setup, even if the public purchase is directed only at capital goods, it tends to crowd out (at least weakly) private expenditures on both consumption and capital goods. This result is rather intuitive. Within a representative agent, the government purchase cannot increase the desire to trade as one trades only with oneself, and any trades that are possible after the purchase by the government were also possible before and therefore there is no reason to expect either amplification or positive spill-over. However, the same logic does not follow once there is more than one type of individual. If agents differ in their sector of employment, then the government purchase of capital goods transfers income to capital goods producers which will generally lead them to buy more consumptions goods. In fact, in such a case the government action is changing the gains from trade between the different types of workers; it is favoring trade from the producers of consumption goods - who need income to pay taxes- toward the producers of capital goods - which have increased net revenues. While the precise outcomes can vary, Proposition 6 indicates that given the conditions under which we obtained perception driven fluctuations in Section 3, we find that government expenditures can create spillovers and positive aggregate co-movement.

Proposition 6 If the conditions of Proposition 3 are met, then an increase in government purchases of capital goods will lead to an increase in private purchases of consumption goods (a spillover effect), and create positive co-movement. However, it will not increase the private purchase of capital goods (no amplification effect).

Recall that the conditions stated in Proposition 3 implied an upward sloping aggregate capital supply curve and a downward sloping capital demand curve. In such a case, an increase in government purchases of capital goods tends to shift out the aggregate demand for capital, increasing the aggregate quantity purchased and increasing the price of capital. Individual demand curves for capital tend to shift in because of the tax increases. Hence we can see why there is no amplification effect as the equilibrium price of capital increases and agents have downward sloping demand curves. However, through this process agents in the capital sector are getting higher income which leads them to want to consume more. This is where the gains from trade arise. The producers of consumptions goods are willing to trade with the producers of capital goods as the added income will help them pay taxes. Could it be the case that the income effect on the producers of capital is great enough to lead such producers to actually substantially increase their purchase of capital and create amplification? Under the assumptions of Proposition 6 this cannot happen since aggregate capital demand is downward sloping.

Proposition 5 and 6 provide insight to how allowing for explicit gains from trade between individuals can change the qualitative effects of fiscal policy. In particular, it is interesting to note that the framework has the potential to explain why consumption may increase following an increase in government purchases, as has been found empirically by Blanchard and Perotti [2002], Fatas and Mihov [2001] and Galí, López-Salido, and Vallés [2007]. However, Proposition

\footnotetext{
${ }^{15}$ See for example Baxter and King [1993] Burnside, Eichenbaum, and Fisher [2004] and Ramey and Shapiro [1998].
} 
6 does not address the issue of whether government spending can create multipliers greater than one. In the case of purchases of investment goods, this would happen if the spillover effect on consumption goods was large enough and that the crowding out effect on private investment is not to important. While getting multiplier effects greater than one in our setting is not difficult, it does depend on many issues. Since we have not found any insightful general conditions that clarify when a multiplier greater or smaller than one may arise, we turn to now to illustrating the possibilities and difficulties using simple examples.

\subsubsection{Illustrating how taxing decisions affect the size of a government purchase multiplier}

This section will illustrate that the size of a government spending multiplier depends critically on whether the spending package and taxes are set to create gains from trade or not. For example, as will be shown, government spending that is associated with sectoral taxes which are proportional to the sectoral expenditures creates no multiplier effect (multiplier equals one at best). What is important for government spending to have a multiplier effect is that it leads to differential income effects across agents, and it is these income effects that create gains from trade. Interestingly, this analysis helps shed light on why private investment may be seen as having a multiplier while government spending may not. The reason being that investment driven by perception is an increase in demand that is not balanced in terms of its income effects and hence creates gains from trade. Government policy can try to replicate such an effect but it needs to not offset sectoral expenditure with equivalent sectoral taxes.

To see this mechanism, consider the same two period environment as we have been focusing upon, that is, there are two types of agents with preferences

$$
\begin{aligned}
U^{i}\left(C^{i}, L^{i}\right) & =\ln C^{i}+\phi\left(1-l^{i}\right), \\
V^{i}\left(K^{i}\right) & =\ln K^{i},
\end{aligned}
$$

where agent 2 produces capital (one-to-one), and agent 1 produces the consumption good (oneto-one). The price of consumption is normalized to 1 , and $P$ represents the relative price of the investment good.

Let us assume that government spending takes the form of an expenditure of 1 (in units of the numeraire) divided between investment goods and consumption goods. Let $\alpha$ be the expenditure on investment goods (so that the real amount of investment purchased will be $\frac{\alpha}{P}$ ), and $1-\alpha$ the expenditure on consumptions goods. ${ }^{16}$ Total taxes need to be equal to 1 , so let us denote by $\beta$ the lump sum tax imposed to the investment sector agent, while $1-\beta$ is the lump sum taxes imposed on the agent in the consumption good sector.

The budget constraint of agent 2 is $C^{2}+P K^{2}=P L^{2}-\beta$, the first order conditions can be expressed as

$$
\begin{gathered}
\frac{P}{P\left(L^{2}-K^{2}\right)-\beta}=\phi, \\
\frac{P}{P\left(L^{2}-K^{2}\right)-\beta}=\frac{1}{K^{2}} .
\end{gathered}
$$

\footnotetext{
${ }^{16}$ The policy could alternatively be specified in terms of real purchases of both goods. This slightly complicates the algebra but provides very similar insights.
} 
The budget constraint of agent 1 is $C^{1}+P K^{1}=L^{1}-(1-\beta)$, the first order conditions can be expressed as

$$
\begin{gathered}
\frac{1}{\left(L^{1}-P K^{1}\right)-(1-\beta)}=\phi, \\
\frac{P}{\left(L^{1}-P K^{1}\right)-(1-\beta)}=\frac{1}{K^{1}} .
\end{gathered}
$$

The market clearing condition for the capital market is

$$
L^{2}=K^{1}+K^{2}+\frac{\alpha}{P}
$$

These five equations ${ }^{17}$ determine $\left\{L^{1}, L^{2}, K^{1}, K^{2}, P\right\}$ as a function of the government policy $\alpha$ and $\beta$.

In the case of no government spending, the equilibrium allocations are given by $L^{1}=L^{2}=\frac{2}{\phi}$, $P=1, K^{1}=K^{2}=\frac{1}{\phi}$. Therefore, GDP in consumption units is equal to $C+p K=\frac{4}{\phi}$

Assume now that the government spends a total of one (in units on consumption) on consumption and investment goods. In such a case, it can be verified that GDP in consumption units is equal to $\frac{4}{\phi}+1+2(\alpha-\beta)$, so the multiplier is $1+2(\alpha-\beta)$. If $\alpha=\beta$ then the multiplier is simply one, as no gains from trade are created. The multiplier is maximized when all the purchases are targeted at the investment sector $(\alpha=1)$, and no taxes are paid in the investment sector $(\beta=0)$. This illustrates that government spending can have a greater effect when sectoral spending is not offset by proportional sectoral taxes. ${ }^{18}$

\subsubsection{Introducing an explicit government sector to illustrate how a large multiplier can arise}

In this second example we want to to illustrate a case where government purchases correspond to the hiring of a particular set of workers, and how this leads to a multiplier of exactly two. To this end, we take the same setup as above but we add one more type of agent. Agent 3 has the same preferences as the others - i.e. $\ln \left(C^{3}\right)+\nu\left(1-L^{3}\right)+\ln K^{3}$, with budget constraint $C^{3}+P K^{3}=w^{3} L^{3}$. Agents of type 3 can only be hired by the government within the current period and so their labor income corresponds to government expenditure: $w^{3} L^{3}=G$, where $G$ is government spending. We assume for simplicity that $G$ is either useless, or enters utility in a separable manner, so its direct effect on decisions can be disregarded. We set taxes to be lump sum and equal on both agent 1 and 2. This model can be solved explicitly, and gives a multiplier of exactly two following an increase in government spending. What happens is that both agent 1 and 2 keep consuming and investing as before, but both work more to supply consumption goods and investment goods to agent 3 who is the beneficiary of government spending.

\footnotetext{
17 This system can be quickly reduced to a system in 3 equations when noting that $K^{2}=\frac{1}{\phi}, P K^{1}=\frac{1}{\phi}$, hence the three relevant equations are $\frac{P}{P\left(L^{2}-K^{2}\right)-\beta}=\phi, \frac{1}{\left(L^{1}-P K^{1}\right)-(1-\beta)}=\phi$ and $L^{2}=K^{1}+K^{2}+\frac{\alpha}{P}$.

18 It may be more appropriate to calculate post spending GDP in baseline prices $\left(-\right.$ i.e., $L^{1}+L^{2}$ instead of $\left.P L^{2}+L^{1}\right)$. In this case, GDP after spending is $\frac{4}{\phi}+1+\frac{(\alpha-\beta)(2-\beta \phi)}{1+\phi(\alpha-\beta)}$, which again implies a multiplier of 1 if $\alpha$ equals $\beta$ (sectoral balancing of expenditures and taxes).
} 
The equilibrium conditions in this case are:

$$
\begin{aligned}
\frac{P}{P\left(L^{2}-K^{2}\right)-\frac{G}{2}} & =\nu, \\
\frac{1}{K^{2}} & =\nu, \\
\frac{1}{\left(L^{1}-P K^{1}\right)-\frac{G}{2}} & =\nu, \\
\frac{1}{K^{1}} & =P \nu, \\
\frac{w^{3}}{w^{3} L^{3}-P K^{3}} & =\nu, \\
\frac{P \nu}{w^{3}} & =\frac{1}{K_{3}} .
\end{aligned}
$$

In this model, the solution takes the following form: $P=1$ (hence the price of investment is not affected by government spending), $K^{3}=\frac{G}{2}, K^{2}=\frac{1}{\nu}, K^{1}=\frac{1}{\nu}$ and therefore $K=L^{2}=\frac{G}{2}+\frac{2}{\nu}$, $C^{1}=C^{2}=\frac{1}{\nu}, C^{3}=\frac{G}{2}$ and $L^{1}=\frac{2}{\nu}+\frac{G}{2}=C$

Therefore an increase in $G$ increases aggregate consumption, investment and employment. Let us define GDP as $C+P K+G$. We therefore have $G D P=\frac{4}{\nu}+2 G$. The multiplier of exactly 2 derived here is interesting as it arises from the fact that the government expenditure creates income for type 3 individuals, which they use to buy goods from other agents. As they use all their increased income to buy either consumption goods or investment goods, this leads to an increase of both aggregate consumption and investment of the same amount as the original outlay by the government. The other agents are willing to supply such goods to type 3 agents since they need the extra revenue to pay taxes. It is in this sense that the government intervention is increasing the gains from trade between type 3 individuals and the others.

\subsection{Sticky price, inflation and monetary policy}

Up to now we have provided examples of how labor market segmentation - which gives rise to gains from trade between individuals - can bring insights about the functioning of the macroeconomy when prices adjust to to their Walrasian levels. In this section we want to illustrate how introducing explicit gains from trade into a standard sticky price model can also alter conventional wisdom regarding the determination of inflation and the role of monetary policy in responding to "demand" shocks. In particular, we want to contrast the functioning of a baseline New Keynesian model where there is a representative agent to one that we augment to include gains from trade between individuals. The baseline model we have in mind is the textbook example of Galí [2008].

\subsubsection{A standard New Keynesian model}

Consider en environment with one representative agent who consumes an aggregate consumption good that is a basket of monopolistically produced consumption goods indexed by $j$ :

$$
c_{t}=\left(\int_{0}^{1} c_{j t}^{\frac{\varepsilon-1}{\varepsilon}} d j\right)^{\frac{\varepsilon}{\varepsilon-1}} .
$$


with $\varepsilon>1$. This agent is infinitely lived and has preferences over consumption and leisure given by

$$
\sum \beta^{t}\left(\ln \left(c_{c t}\right)+\Phi\left(1-\ell_{C t}\right)\right)
$$

with $1>\beta>0$ and $\Phi>0$.

Each monopoly $j$ produces a variety of consumption good according to the following constant return to scale technology:

$$
C_{j t}=A_{t} L_{j t}
$$

where $A_{t}$ is a technological shock. Prices are sticky and we assume Calvo price setting: each consumption firm may reset its price with probability $1-\theta$ in each period, $\theta \in[0,1]$. Finally, there is a central bank that sets the nominal interest rate following a Taylor rule.

In the flexible price allocations, labor is constant, so that natural output is given by $\widehat{y}_{t}^{n}=\widehat{A}_{t}$ and the natural real interest rate, denoted $\widehat{\rho}$, satisfies $\widehat{\rho}_{t}^{n}=E_{t} \widehat{A}_{t+1}-\widehat{A}_{t}$ (where hats denote log deviations from the steady state). ${ }^{19}$ In the sticky price model, we define the output gap $\widetilde{y}_{t}$ as the deviation of output from the natural level $\widehat{y}_{t}-\widehat{y}_{t}^{n}$. The equilibrium allocations are given by a dynamic IS equation, a New Keynesian Phillips curve and Taylor rule (that relates the nominal interest rate to output gap and inflation):

$$
\left\{\begin{aligned}
\widetilde{y}_{t}= & -\left(\widehat{\imath}_{t}-E_{t} \widehat{\pi}_{t+1}-\widehat{\rho}_{t}^{n}\right)+E_{t} \widetilde{y}_{t+1}, \\
\widehat{\pi}_{t}= & \beta E_{t} \widehat{\pi}_{t+1}+\lambda \widehat{y}_{t} \\
+ & \text { Taylor rule }
\end{aligned}\right.
$$

where $i$ is the nominal interest rate, $\pi$ the rate of inflation and where where $\lambda$ is a function of the model parameters.

What happens in this environment if agents expect $A_{t+1}$ to be high? This increases the demand for current consumption through the expectation of future income. If the Taylor rule is such that it does not immediately increase interest rates enough to fully offset the increased demand, this will lead to inflation. In particular, let us focus on the New Keynesian Phillips curve. The increased expectation of $A_{t+1}$ does not directly enter into this curve, and therefore if a higher expectation for this variable leads to an increase in output it will necessarily place upward pressure on inflation as the natural level of output is not affected by the more optimistic expectation that increases the demand for consumption goods. Accordingly, it is optimal in such a setting for the monetary authorities to completely offset such a demand shock by increasing interest rates sufficiently to leave output unaffected. In contrast, if the shock was to $A_{t}$, which would be referred to a supply shock as it changes the current capacity of the economy to produce, it would be reasonable to accommodate the shock and let output increase while simultaneously maintaining stable inflation. This set up provides a nice illustration of the textbook prescription that in order to keep stable inflation, monetary authorities need to strongly counteract demand shock but need to accommodate supply shocks. Moreover in this framework, if the economy goes into recession (expansion) due to a fall (increase) in demand - as opposed to a reduction in supply capacity - this should put substantial downward (upward) pressure on prices. We now want to illustrate how such results change when we add another agent into this economy such that there are now gains from trade between individuals.

\footnotetext{
${ }^{19}$ Details of the main derivations of this section are presented in appendix C.
} 


\subsubsection{Adding gains from trade}

Let us consider the same simple New Keynesian setting which we now augment to include explicit gains from trade between individuals. Some agents will produce the consumption good and some the investment good. Although we allow for capital accumulation and agents heterogeneity, we will make functional form assumptions to preserve tractability of the model. When the number of investment good workers is driven to zero, the model will converge to the simple New Keynesian model presented above.

The economy is populated of $n_{C}$ consumption good workers and $n_{X}$ investment good workers. All agents consume an aggregate consumption good, that is a basket of monopolistically produced consumption goods indexed by $j$. Denoting $c_{C t}$ and $c_{X t}$ the consumption of a representative consumption good worker and of a representative investment good worker, we have:

$$
\begin{aligned}
& c_{C t}=\left(\int_{0}^{1} c_{C j t}^{\frac{\varepsilon-1}{\varepsilon}} d j\right)^{\frac{\varepsilon}{\varepsilon-1}}, \\
& c_{X t}=\left(\int_{0}^{1} c_{X j t}^{\frac{\varepsilon-1}{\varepsilon}} d j\right)^{\frac{\varepsilon}{\varepsilon-1}} .
\end{aligned}
$$

Consumption workers are all identical, infinitely lived and have preferences over consumption and leisure given by

$$
\sum \beta^{t}\left(\ln \left(c_{c t}\right)+\Phi\left(1-\ell_{C t}\right)\right)
$$

with $1>\beta>0$ and $\Phi>0$. For simplicity, investment workers are myopic ${ }^{20}$, and do not make intertemporal choices: they do not own any assets nor have any liabilities, and just consume their current labor income. Their preferences are given by

$$
U\left(c_{X t}-\Psi \frac{\ell_{X t}^{1+\gamma}}{1+\gamma}\right)
$$

with $\gamma>0$ and where $U$ is a concave and $C^{2}$ function.

Each monopoly $j$ produces a variety of consumption good according to the following constant return to scale technology:

$$
C_{j t}=\Theta_{t} K_{j t}+A_{t} L_{C t} .
$$

Capital and labor are perfectly substitutable in the production of consumption good varieties, which allows for an easier analytical solution. $\Theta_{t}$ is a capital specific stochastic technological shock and $A_{t}$ a labor specific one. The investment good is produced by a representative competitive firm, with labor only, and according to the constant return to scale technology:

$$
X_{t}=B L_{X t}
$$

Capital accumulates according to the following law of motion, with $\delta \in[0,1]$ :

$$
K_{t+1}=(1-\delta) K_{t}+X_{t}
$$

In this section, we will assume that there is full depreciation $(\delta=1)$. In appendix $(\mathrm{C})$, we present the equations for the more general case. As before, there is a monopoly for each variety

\footnotetext{
${ }^{20}$ See example 2 of section 3.3 for a justification.
} 
of the consumption good, while there are competitive markets in labor, investment good, bond and money. Money remains the numéraire. Total real output (or real GDP) is measured in units of consumption and is defined as

$$
Y_{t}=C_{t}+\frac{R_{t}}{P_{t}} X_{t}
$$

where $P_{t}$ is the consumption goods price index and $R_{t}$ is the price of the investment good. We assume Calvo price setting. In order to embed the standard model of Galí as a special case of our model when $n_{X}=0$, we assume that prices are sticky in the consumption good sector only. Each consumption firm may reset its price with probability $1-\theta, \theta \in[0,1]$. In the investment good sector, we maintain the assumption of flexible prices.

Interestingly the log linear approximation for this extended model can be written in a form very similar to the baseline model, that is, it can be written as

$$
\left\{\begin{aligned}
\widetilde{y}_{t}= & -\zeta\left(\widehat{\imath}_{t}-E_{t} \widehat{\pi}_{t+1}-\widehat{\rho}_{t}^{n}\right)+E_{t} \widetilde{y}_{t+1} \\
\widehat{\pi}_{t}= & \beta E_{t} \widehat{\pi}_{t+1}+\lambda \zeta^{-1} \widetilde{y}_{t}, \\
+\quad & \text { Taylor rule, }
\end{aligned}\right.
$$

where $\lambda$ and $\zeta$ are functions of the model parameters. In the baseline New Keynesian model, the natural rate of output was given by $\widehat{y}_{t}^{n}=\widehat{A}_{t}$, and therefore only varied if $A_{t}$ varied. However, in our extended model, the natural or non-inflationary level of output is given by

$$
\widehat{y}_{t}^{n}=\phi_{2} A_{t}+\phi_{1} E_{t}\left[\widehat{\Theta}_{t+1}-\widehat{A}_{t+1}\right]=\phi_{2} A_{t}+\phi_{1} \widehat{\Omega}_{t},
$$

where $\widehat{\Omega}_{t}=E_{t}\left[\widehat{\Theta}_{t+1}-\widehat{A}_{t+1}\right]$ captures a change in expectations that increases the relative productivity of capital. We can therefore write the Phillips curve alternatively as:

$$
\widehat{\pi}_{t}=\beta E_{t} \widehat{\pi}_{t+1}+\lambda \zeta^{-1}\left(\widehat{y}_{t}-\phi_{2} A_{t}-\phi_{1} \widehat{\Omega}_{t}\right) .
$$

Now let us consider how this economy reacts to the belief that $\widehat{\Theta}_{t+1}-\widehat{A}_{t+1}$ will be high as captured by a high value of $\Omega_{t}$. Such a change in perception will induce consumption workers to want to by capital as its return is expected to be high, which will lead them to want to increase their trade with investment workers. It will also induce investment workers to want to buy more capital, and induce them to buy more consumption goods as they feel richer. Following the standard nomenclature, this would appear as a type of demand shock. However, this extended economy does not react to this type of demand shock in the same way that the baseline model does. As can be seen in equation $(P C)$, an increase in output driven by such a change in perception will not necessarily place upward pressure on prices as the natural or non-inflation rate of output has also changed. In $(P C)$ the perception about $\Omega_{t}$ itself enters the Phillips curve, that is, the change in perception makes the output-inflation trade-off better. Hence a monetary authority who would like to stabilize prices would not want to counteract such a demand shock, but instead would like to accommodate it.

In such a framework, if an economy found itself in a recession due to a negative change in perception about the future returns to capital, this would not necessarily place downward pressure on prices. Similarly, if an economy became widely optimistic about the future returns 
to current investment, this could cause a demand driven boom which could be completely compatible with stable inflation. Hence, one can see that a model with explicit gains from trade can behave quite differently, and lead to quite different policy advice, than a model based on a representative agent framework.

Why is it that the two models give such conflicting views about the effects of demand shock on inflation? Actually, the two models are not very different in their implications once the right wording is used. The main lesson from New Keynesian models in terms of inflation is that inflation is created by output movements which depart from the Walrasian counterpart. This lesson remains true in our slightly extended model. What is different in our framework is that perceptions affect the Walrasian equilibrium volumes of trade due to the induced gains from trade between agents. What one should take away from this example is that distinction between demand and supply shocks, which has a long history in macroeconomics, is not a very useful way to organize one's discussion when agents have incentive to trade between themselves. ${ }^{21}$ In other words, what should be viewed as causing inflation is deviation of output from the mutually desirable volume of trade between individuals, knowing that this equilibrium volume of trade is likely to be as sensitive to current changes in supply capacity as it is of perceptions about the future.

\subsubsection{An interpretation of the recent cycles}

Is there any reason to believe that the insight presented above regarding the effects perception driven fluctuations on inflation are relevant for current economic analysis? We believe so. Casual evidence to support this claim is given by Figure 2. The Figure displays, for the United States, Hodrick-Prescott cycles for hours worked and average labor productivity, together with the level of core inflation and investment-output ratio. If we focus exclusively on the last three cycles (the last 30 years), we can see how conventional logic has a hard time explaining these episodes. We can see that the pattern of hours is very similar across the three cycles. The first well know fact about this period is that this set of boom bust cycles in hours happens with very little change in inflation (although inflation is still slightly procyclical over the period, it is barely moving). Using traditional logic, it would appear doubtful that these cycles can be caused by changes in aggregate demand as inflation would be expected to rise as a natural byproduct of a demand driven cycle. At the same time, it is interesting to note that labor productivity and employment have been essentially uncorrelated over the period. This suggests that these cycles were not driven by cyclically high level of productivity. Finally, we can see from the investment to output ratio series that cycles are essentially large booms and bust in investment. The question then arises what has caused these cycles if they are neither driven by neither technological supply shocks nor demand surprises. One easy interpretation of these cycles is that they represent cycles driven primarily by the expectation that current investment will have a high return. The analysis of this paper provides a simple mechanism which can explain the resulting boom-bust cycle while simultaneously being consistent with stable inflation. For the same reasons that long and protracted periods of aggregate booms can be non-inflationary,

\footnotetext{
21 The idea that the demand-supply distinction used in many macroeconomic discussions may not be very meaningful has been emphasized in many contexts over the years. Our contribution here is to present a simple, potentially relevant and very transparent example where the distinction is inappropriaten and likely to mislead policy.
} 
in our framework recessions are not necessarily creating strong deflationary pressures which is also a feature of the period.

\section{Discussion and evidence}

\subsection{Discussion of normative issues}

In our discussion of policy, we have shown how and under what conditions specialized labor markets can (i) explain why a monetary authority that accommodates demand driven booms may not be stimulating inflation, and (ii) explain how government spending in one sector can spillover positively to other sectors and thereby create increased consumption and generalized booms. However, these are positive implications. We have not discussed optimal policy. The first question to focus upon when addressing optimal policy is identify what imperfection is the policy trying to counter. In our setup, there is one sense in which markets are imperfect and it is due to the lack of complete markets to insure against changes in perception. The evidence on consumption presented in the next section will provide support to the notion that agents do not have access to a sufficient array of contingent claims to protect themselves fully from sectoral shocks. In such a case government policy may aim to help the economy replicate as best as possible the type of outcome that would arise with complete markets to share perception risk. To see what such a policy response may look like, we return to our two agent setup where the exogenous disturbance is a change in perception about future returns to capital. While these perceptions could be erroneous, we will treat that here as being shared by the policy makers and discuss only how best to respond given the perception. ${ }^{22}$

Let us consider the environment where we have two types of agents $i=1,2$ of mass 1 , and preferences are given by

$$
U^{i}\left(C^{1}\right)+\nu\left(1-L^{i}\right)+V^{i}\left(K^{i}, \Omega_{1}\right),
$$

with $U_{1}^{i}>0, U_{11}^{i}<0$ and $V_{12}^{i}>0$. Agent 1 can only produce consumption goods, and agent 2 can only produce investment goods. Production technology is one-to-one in both sectors. The variable governing perceptions, $\Omega_{1}$, can take on two values, $\bar{\Omega}>\underline{\Omega}$, where the probability of it taking on the value $\bar{\Omega}$ is $q$.

How can fiscal policy be used in such an environment to an support an ex-ante Pareto optimal outcome? What is needed is that policy be chosen so that marginal utility for each agent is equalized across states. This can be done quite simply with a tax transfer scheme between individuals, which satisfies budget balance and it can in addition be chosen to be fair in the sense of zero expected transfers between the parties. ${ }^{23}$ In particular, if we denote by $T(\bar{\Omega})$ the tax imposed on type 2 agents in the optimistic state, then the fair transfer received in the pessimistic state can be written as $\frac{1-q}{q} T(\bar{\Omega})$. Accordingly, in such a case the transfer to type 1 in the optimistic state is $T(\bar{\Omega})$, and the tax in the pessimistic state is given by $\frac{1-q}{q} T(\bar{\Omega})$. The value for $T(\bar{\Omega})$ that implements a Pareto optimum can be found by solving the Walrasian

\footnotetext{
${ }^{22}$ If the policy makers think the perceptions are erroneous, this would provide a different reason for policy intervention. While this is an interesting and potentially relevant issue, we do not pursue this issue here.

23 The fair aspect is not a requirement for a Pareto optimum, it is simply a way of selecting one allocation in the set of Pareto optima.
} 
Figure 2: U.S. business cycles
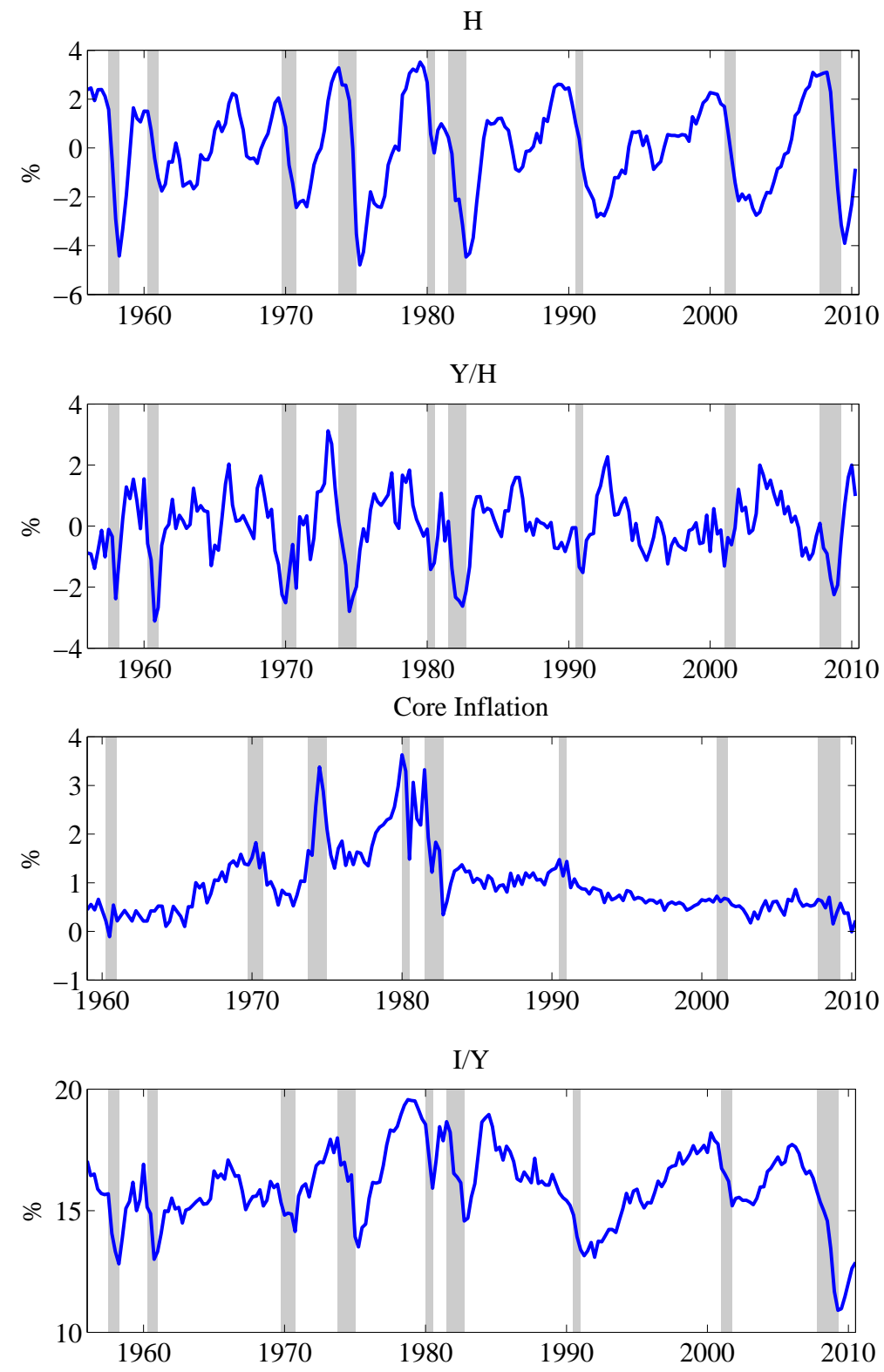

In this Figure, hours worked and average labor productivity are in relative deviations from an Hodrick-Prescott trend with smoothing parameter $\lambda=1600$. Inflation and investmentoutput ratio are unfiltered and expressed in percentage points. Shaded areas represent NBER recession periods. Data are quarterly, and run from 1956Q1 (1959Q1 for core inflation) to 2010Q3. Core inflation is the growth rate of "Consumer Price Index for All Urban Consumers: All Items Less Food 85 Energy" (CPILFESL in FRED). Investment to output ratio is computed using current price Gross domestic product $\mathrm{A} 191 \mathrm{RC} 1$ and Gross private domestic investment A006RC1, as taken from Table 1.1.5. of the NIPA published by the Bureau of Economic Analysis. Hours worked are taken from BLS (Series Id: PRS85006033) and concern the nonfarm business sector. 
equilibrium for the two states and imposing the conditions that

$$
U_{1}^{2}\left(\left(p(\bar{\Omega})\left(L^{2}(\bar{\Omega})-K^{2}(\bar{\Omega})\right)-T(\bar{\Omega})\right)=U_{1}^{2}\left(\left(p(\underline{\Omega})\left(L^{2}(\underline{\Omega})-K^{2}(\underline{\Omega})\right)+\frac{1-q}{q} T(\underline{\Omega})\right) .\right.\right.
$$

Recall that the equilibrium conditions for the case where $\Omega_{1}=\bar{\Omega}$ will be

$$
\begin{aligned}
p(\bar{\Omega}) U_{1}^{2}\left(p(\bar{\Omega})\left(L^{2}(\bar{\Omega})-K^{2}(\bar{\Omega})\right)-T(\bar{\Omega})\right) & =\nu, \\
p(\bar{\Omega}) U_{1}^{2}\left(p(\bar{\Omega})\left(L^{2}(\bar{\Omega})-K^{2}(\bar{\Omega})\right)-T(\bar{\Omega})\right) & =V_{1}^{2}\left(K^{2}(\bar{\Omega}), \bar{\Omega}\right), \\
K^{1}(\bar{\Omega})+K^{2}(\bar{\Omega}) & =L^{2}(\bar{\Omega}), \\
U_{1}^{1}\left(\left(L^{1}(\bar{\Omega})-p(\bar{\Omega}) K^{1}(\bar{\Omega})\right)+T(\bar{\Omega})\right) & =\nu, \\
\left.p(\bar{\Omega}) U_{1}^{1}\left(L^{2}(\bar{\Omega})-p(\bar{\Omega}) K^{2}(\bar{\Omega})\right)+T(\bar{\Omega})\right) & =V_{1}^{2}\left(K^{1}(\bar{\Omega}), \bar{\Omega}\right) .
\end{aligned}
$$

The resulting policy will be one that taxes workers in the capital good sector when agents are optimistic, and transfers fund to them when agents are pessimistic. These transfers induce full consumption smoothing for workers in the capital sector and thereby stabilize the price of capital. It should be noted that such an intervention will tend to increase the volatility of capital purchases, as well as employment in the capital goods sector, as optimal intervention does not require stabilizing investment. If fact, taking as given the changing perceptions of the future return to capital, it is optimal to have investment fluctuate significantly in response to these changes. ${ }^{24}$ It is worth noting that unemployment insurance in many countries plays a role somewhat similar to the optimal policy described here. Unemployment insurance tends to dis-proportionally transfer income to workers in capital good sectors when the economy is doing badly. Such transfers are generally based on past wages and therefore will tend to keep up current wages and the price of capital in recessions. This will likely amplify employment movements in the capital good sector, but this is precisely what is optimal when consumption is stabilized. ${ }^{25}$

\subsection{Evidence of labor market segmentation and imperfect insurance}

Gains from trade between individuals in the goods markets arise when agents don't produce the same goods. If agents can always allocate their time without frictions between different sectors of production then there would be no explicit gains from trade in these markets. Even if labor supply is lumpy, as long as agents can move freely between sectors their labor income should not differ depending on the sector they happened to have chosen at a point in time.

${ }^{24}$ If we don't assume separable or quasi linear preferences, the analysis is not much changed. An ex-ante Pareto optimum can be obtained by simply setting a tax transfer scheme that keeps the marginal utility of type 2 equal across the two states, that is

$$
U_{1}^{2}\left(p(\bar{\Omega})\left(L^{2}(\bar{\Omega})-K^{2}(\bar{\Omega})\right)-T(\bar{\Omega}), 1-L^{2}(\bar{\Omega})\right)=U_{1}^{2}\left(p(\underline{\Omega})\left(L^{2}(\underline{\Omega})-K^{2}(\underline{\Omega})\right)+\frac{1-q}{q} T(\underline{\Omega}), 1-L^{2}(\underline{\Omega})\right) .
$$

25 One of the aspects we find interesting about adopting an approach with explicit gains from trade is that it simultaneously provides insight into why optimism and pessimism may be at the center of business cycle fluctuations, and also provide a explanation to why many governments try to counter such cycles by use of transfer programs and other automatic stabilizers. 
In this section we want to briefly examine the extent to which individual-level labor income varies over the cycle depending on what sector one tends to be associated with at the beginning of a period.

To look at this issue, we used data from the PSID over the period 1968-2007. The PSID interviews families during the March-April period ${ }^{26}$ and asks them questions about their income over the previous calendar year. They also report, among others, information related to age, educational attainment and sector of employment. These data were collected yearly between 1968-1997, and then bi-annually since 1999.

We are interested in examining whether the growth in labor income of the head of household was systematically related to the aggregate performance of the sector (industry) to which the head was attached at the beginning of the period. More precisely, our dependent variable is the growth (log-difference) in the labor income of head of household over either a two-year period or a one-year period. When looking at one year rates, we can use data only from 1969 up to $1997 .{ }^{27}$ When using two year growth rates, we use non-overlapping periods from 1969-2007.

Our main regressor is the growth rate of either the industry level wage bill or employment rate associated with the head's sector of employment at the time of the interview. These national level variables were taken from the Bureau of Economic Analysis (BEA) National Income and Product Account (NIPA) Tables. ${ }^{28}$

The other regressors we include in the specification are a full set of year dummies, a full set of age dummies, a control for the highest level of educational attainment, dummies for the sector of employment, and interactions between age-time, education-age and education-time. The coefficients on these later variables are not reported in the table.

In a second set of regressions, we use as the dependent variable the growth rate (logdifference) in the household's total food consumption, and relate this, again to the industrylevel growth rates of either the wage bill or the employment rate of the industry the household head works in at the time of the interview. Total food consumption is constructed as the sum of expenditures on food at home and food out. ${ }^{29}$ Food consumption data is missing for 1973, 1988, 1989. There was also a change in the wording of the questions in 1994, so we do not calculate any growth rates that overlap this period. Our sample is chosen so that we cover the same years and a similar sample when looking at either the behavior of income or consumption. ${ }^{30}$

Column 1 of Table 1 reports results associated with regressing the growth over two years in individual level labor income on the set of individual level controls noted above and on the growth in national level employment for the sector with which the individual was associated at the beginning of the period. National level growth in employment is calculated over the same

\footnotetext{
${ }^{26}$ In most cases, although some interviews also occur during other months.

27 We cannot use 1968 because we do not have aggregate data for that year.

28 Specifically, Section 6, Table 6.3: Wage and Salary Accruals by Industry, and Table 6.5: Full-Time Equivalent Employees by Industry. For the correspondence used to match the industry codes in the NIPA Tables (which are SIC and NAICS) and the ones in the PSID (which are Census Codes), see Table B.1.

${ }^{29}$ We also add expenditure on food delivered, when available.

30 This restricts the sample years to those in which 2-year growth rates in food consumption data is available, so the years included are 1969, 1975-1985, 1991, and 1995-2005. For consistency, when using the growth in labor income as the dependent variable, we also examine results when using all years available as opposed to using only the years for which consumption data is available as well. Results are not significantly different. We also used the trimming criteria that consumption growth could not increase or decrease by more than $100 \%$ over a two year period.
} 
period as growth in individual level income. Since the specification also includes a set of time dummies, the estimate of the effect of sectoral level growth in employment on individual level income is identified off the cross-sectional variation where we are comparing the growth rate in labor income at a point in time between individuals who happen to be in different sectors of employment at the time of the interview. If labor markets were completely integrated, and given we are controlling for common time effects, then individual level outcomes should not be systematically related to aggregate outcomes for any particular sectors.

In Column 1 individuals are classified into three broad sectors: the government sector, the capital goods sector defined as manufacturing and construction, and a residual sector which captures all other sectors including the main product units for current consumption goods. ${ }^{31}$ The effect of changes in aggregate employment growth on individual level income is estimated to be close to .5. Recall that an individual is linked to a sector by his beginning of period classification. This coefficient suggests that when comparing two individuals that were initially attached to two different sectors, the individual initially attached to the sector where aggregate employment grew by an extra $1 \%$ over two years saw his labor income grow by an additional $.5 \%$. This effect is quite sizable, suggesting that individuals are not sufficiently mobile between sectors to constantly induce equivalent returns across sectors.

In Column 2 of the table we replace as regressor aggregate employment growth in the sector by growth in the wage bill in the sector. This change in the indicator for sectoral growth gives an almost identical result, suggesting that changes in the wage bill are dominated by changes in employment, not changes in average wages. As we generally found that these two aggregate indicators gave similar results, we will focus exclusively on the effects of the aggregate employment growth variable in the remaining results. In Column 3 , we drop observations where individuals were linked to the government sector. This again does not change significantly the estimate of the effect of sectoral growth on individual income growth. In Column 4, we take a slightly more detailed view of sectors by linking individuals to 10 different sectors i.e. Agriculture, Forestry and Fishing; Mining; Construction; Manufacturing; Transportation, Communication and Public Utilities; Wholesale Trade; Retail Trade; Finance, Insurance and Real Estate; Services; and Government. ${ }^{32}$ Again, this changes very little the main estimated coefficient. ${ }^{33}$ As individuals with different levels of educational attainment had quite distinct labor market outcomes over the period we cover, in Column 5 we re-estimate the specification of Column 4 focusing only on individuals with an educational attainment of high school or less. Results for more highly educated individuals are similar but slightly less precise. Controlling for education in this alternative way also does not change significantly our results suggesting that the results are unlikely to be driven simply by some compositional effect across education groups.

In Columns 6, 7 and 8 of Table 1 we report results based on one year intervals instead of two year intervals. As the PSID only collected yearly observations until 1997, these results cover

\footnotetext{
${ }^{31}$ Individuals that did not declare an industry because of unemployment status were included in the residual category.

${ }^{32}$ Details of the links used between the PSID classification and the NAICS are detailed in Appendix B.

${ }^{33}$ In the specification using 10 sectors we cluster standard errors at the sectoral level. The effect of clustering has very little effect on the standard errors. In the case of 2 or 3 sectors we did not cluster standard errors as the number of sectors is too small. When we did try to cluster in such specifications, the standard errors become very small, which seemed unreasonable.
} 
only the period up to $1997 .{ }^{34}$ In Column (6) we report results for the 3 sector specification, Column 7 corresponds to the 2 sector specification as was the case in Column 3, and finally Column 8 reports results for the 10 sector specification. Somewhat surprisingly, the results for the one year specification are very similar in magnitude to those observed in the 2-year specification, suggesting that the segmentation likely lasts more than a year.

The results from Table 1 provide support to the notion that, at least at frequencies relevant for business cycle analysis, labor markets across sectors appear segmented. In particular, these results suggest that the mobility across sectors is not sufficient to equate the returns to labor between individuals initially attached to different sectors. While such a segmentation of the labor markets is a necessary condition underlying our results regarding how changes in perception can cause positive aggregate co-movement, it is also necessary that such sectoral effects translate themselves at least in part to differences in consumption behavior. For this reason in Table 2 we examine the link between sectoral outcomes and individual level consumption behavior. The structure of the results in the Table is almost identical to that of Table 1 except for the fact that we change the dependent variable. All the regressors and the sample decisions are the same as in Table 1. The only difference is that now the dependent variable is the change in the consumption of food for the household as opposed to changes in the labor income of the head of household.

While consumption of food is a quite narrow measure of consumption, it is the main consumption variable available in the PSID. The estimated effects in Table 2 are considerably smaller than in Table 1, but are nevertheless significant and sizable. The fact that the coefficients are smaller should not be surprising as it is well established that people smooth their consumption over time in response to temporary income shocks and further the measure of income used in Table 1 is likely to be much more volatile than disposable family income due to taxes and transfer payments such an unemployment insurance. The main result we take from Table 2 is the observation that family level consumption behavior appears to be significantly affected by the the performance of the sector with which the head was initially associated. This suggests that asset and insurance markets, while important in helping smooth income, are likely insufficient (or not sufficiently used) to entirely protect individuals from temporary shocks to their sectors of employment. ${ }^{35}$

\footnotetext{
34 The years with the required data are 1969-1970, 1972, 1974-1985, 1990-1991, and 1994-1995.

35 Our results on consumption are consistent with the results of Cochrane [1991], Dynarski and Gruber [1997] and Blundel, Pistaferri, and Preston [2009] which document that individual level food consumption in the PSID responds to unemployment shocks.
} 
Table 1: Effect of Sectoral Growth on Individual Income.

\begin{tabular}{|c|c|c|c|c|c|c|c|c|}
\hline & $\frac{2 \text {-year }}{(1)}$ & $\frac{2 \text {-year }}{(2)}$ & $\frac{2 \text {-year }}{(3)}$ & $\frac{2 \text {-year }}{(4)}$ & $\frac{2 \text {-year }}{(5)}$ & $\frac{1-\text { year }}{(6)}$ & $\frac{1 \text {-year }}{(7)}$ & $\frac{1-\text { year }}{(8)}$ \\
\hline$\Delta \operatorname{Emp}$ & $\begin{array}{l}.542 \\
(.209)\end{array}$ & & $\begin{array}{l}.468 \\
(.244)\end{array}$ & & & & & \\
\hline$\Delta \mathrm{W}$-bill & & $\begin{array}{l}.525 \\
(.175)\end{array}$ & & & & & & \\
\hline$\Delta$ Emp-10 & & & & $\begin{array}{l}.450 \\
(.143)\end{array}$ & $\begin{array}{l}.563 \\
(.131)\end{array}$ & & & \\
\hline$\Delta \operatorname{Emp}$ & & & & & & $\begin{array}{l}.535 \\
(.170)\end{array}$ & $\begin{array}{l}.579 \\
(.193)\end{array}$ & \\
\hline$\Delta$ Emp-10 & & & & & & & & $\begin{array}{l}.471 \\
(.059)\end{array}$ \\
\hline Obs. & 49338 & 49338 & 45469 & 45430 & 23173 & 68863 & 63677 & 61224 \\
\hline$R^{2}$ & .028 & .028 & .028 & .027 & .026 & .017 & .018 & .018 \\
\hline
\end{tabular}

Note: Dependent variable: log change in real income from wages and salaries. The main regressor $(\Delta$ Emp) is the log change in employment at the national level for the sector of employment to which the individual was attached to at the beginning of the period. $\Delta W$-bill corresponds to the change in the wage bill per sector. See main text for details on the additional controls included in the regressions but not reported in the table.

Table 2: Effect of Sectoral Growth on Household Consumption

\begin{tabular}{|c|c|c|c|c|c|c|c|c|}
\hline & $\frac{2 \text {-year }}{(1)}$ & $\frac{2 \text {-year }}{(2)}$ & $\frac{2 \text {-year }}{(3)}$ & $\frac{2 \text {-year }}{(4)}$ & $\frac{2 \text {-year }}{(5)}$ & $\frac{1-\text { year }}{(6)}$ & $\frac{1 \text {-year }}{(7)}$ & $\frac{1 \text {-year }}{(8)}$ \\
\hline$\overline{\Delta \mathrm{Emp}}$ & $\begin{array}{c}.268 \\
(.092)\end{array}$ & & $\begin{array}{l}.267 \\
(.104)\end{array}$ & & & & & \\
\hline$\Delta \mathrm{W}$-bill & & $\begin{array}{l}.236 \\
(.078)\end{array}$ & & & & & & \\
\hline$\Delta$ Emp-10 & & & & $\begin{array}{l}.143 \\
(.052)\end{array}$ & $\begin{array}{l}.112 \\
(.053)\end{array}$ & & & \\
\hline$\Delta \mathrm{Emp}$ & & & & & & $\begin{array}{l}.200 \\
(.118)\end{array}$ & $\begin{array}{c}.274 \\
(.129)\end{array}$ & \\
\hline$\Delta$ Emp-10 & & & & & & & & $\begin{array}{l}.208 \\
(.077)\end{array}$ \\
\hline Obs. & 67758 & 67758 & 63686 & 52270 & 26898 & 89008 & 83942 & 65503 \\
\hline$R^{2}$ & .014 & .014 & .013 & .016 & .015 & .005 & .005 & .006 \\
\hline
\end{tabular}

Dependent variable: log change in real income from wages and salaries. The main regressor $(\Delta E m p)$ is the log change in employment at the national level for the sector of employment to which the individual was attached to at the beginning of the period. $\Delta W$-bill corresponds to the change in the wage bill per sector. See main text for details on the additional controls included in the regressions but not reported in the table. 


\subsection{Related literature}

The aim of this paper has been to illustrate how introducing explicit intra-temporal gains from trade between individuals can shed light on a set of macroeconomic phenomena. In particular, we have shown how labor market specialization can help explain (i) perception driven booms and busts, (ii) government spending having positive effects on private consumption, and (iii) non-inflationary demand driven expansion and non-deflationary busts. While a strength of the approach is to offer a simple unified explanation for such behavior, there are alternative models which can also explain some of these features. The related literature is obviously expansive and therefore an exhaustive review is not possible here. Nonetheless, it appears relevant to discuss a few alternatives that aim to address similar issues and clarify some of their different implications. First, standard sticky price models can explain perception driven booms and busts if the conduct of monetary policy is stated in a particular form. But when sticky prices are central to the mechanism, it implies that inflation will also respond to perception changes in a systematic way, which contrasts with our approach where such fluctuations can arise without any systematic movement in inflation. At this point it is unclear which view is more empirically relevant but they are very distinct mechanisms with different implications which eventually should be possible to evaluate. The sticky price model with a representative agent can also explain why government expenditures may increase private consumption, but as discussed in Bilbiie [2011] the mechanism is rather subtle as it only arises when agents preferences are nonseparable between consumption and leisure. In contrast, the mechanism in our model is quite transparent as government expenditures will cause increases in consumption if the expenditures create gains from trade between those benefiting from the government expenditures and those that produce consumption goods.

If we move away from sticky price models, there is also an important literature aimed at explaining perception driven booms and bust ${ }^{36}$ within a flexible price setting. A notable example of this literature is the paper by Jaimovich and Rebelo [2009]. ${ }^{37}$ The mechanism by which optimism about the future leads to increase in current economic activity in the Jaimovich and Rebelo environment is very different to the one in the current paper. In particular, the two key mechanisms in the Jaimovich and Rebelo framework are (i) that optimism about the future leads to a decrease in the price of investment goods today - because of adjustment costs to investment- and (ii) that a reduction in the price of capital today leads to increased labor productivity today and therefore labor demand given the incentives to utilize capital more intensely. Such a mechanism is rather subtle when compared to our mechanism based on labor market specialization whereby optimism about future returns to holding capital favors trade between agents in the consumption sector and those in the investment sector. ${ }^{38}$ At this point in

\footnotetext{
${ }^{36}$ Here we do not consider the recent literature that uses measures of optimism to examine whether perceptions may be important in fluctuations (see for example Farmer and Guo [1995], Carrol [2003], Harrison and Weder [2006] Barsky and Sims [2010] and Leduc and Sill [2010]).

37 Other relevant contributions are Den Haan and Kaltenbrunner [2009], Eusepi and Preston [2009], Beaudry and Portier [2004], Beaudry and Portier [2007] and Schmitt-Grohé and Uribe [2008] among others. An important difference between this literature and the current paper is that this literature does not generally try to offer a unified explanation to how perception changes and government spending may induce macroeconomic comovements.

38 Our approach views perception changes as creating sectoral shocks, in particular creating shocks to the investment sector relative to the consumption sector. In this dimension our framework shares ideas in the sectoral shock literature as pioneered by Lilien [1982].
} 
time, we are unsure which mechanism is more empirically relevant but this also offers relevant questions for future work.

\section{Conclusion}

Two of the key questions in macroeconomics are: what causes business cycle fluctuations and to what extend can or should government mitigate such fluctuations? In this paper we have shown how a macroeconomic model with explicit gains from trade between individuals may provide a useful framework to help frame these issue. For example, when thinking whether any exogenous change will cause an expansion or a recession, the aim of this paper is to suggest that a meaningful way to pose the question is to ask is whether the impinging force will expand or decrease the set of mutually desirable trades between individuals working in different sectors of the economy. In such a framework an expansion is seen as a period when there are substantial gains from trade between individuals in the different sectors of the economy, while a recession where the amount of perceived gains from trade is low. Similarly, if thinking about whether a government policy will reduce or exacerbate fluctuations, one should ask how the intervention will affect the gains from trade between individuals in the different sectors. Obviously for such an approach to be relevant, it must be the case that workers are not perfectly mobile between sectors in the short run. Since such an assumption seems rather plausible, it is not very surprising that considerable support for it can be found in PSID data.

One of the areas where we believe a gains from trade approach may be most helpful is with respect to understanding fluctuations driven by changes in perceptions about the future (whether these be rational or irrational perceptions). In the business press and in the public at large it is common to think of changes in sentiment as a quintessential cause of macroeconomic fluctuations. However, most modern macroeconomic models have certain drawbacks, or work through subtle mechanisms to explain such outcomes. For example in most New Keynesian models, depending on the monetary policy in place, a perception driven boom should either cause consumption and investment to move in opposite directions or cause inflation to increase substantially. Given our experience over the last thirty year with cycles that appear primarily driven by perceptions of regarding the returns to investment, none of these features are very compelling. In contrast, once one adopts a framework where labor markets are segmented across different types of goods, we have shown that it is rather easy to generate perception driven booms where consumption, investment and the price of capital (as possibly captured by the stock market) all increase together without directly putting pressure on inflation.

\section{References}

Barro, R. J., And R. G. King (1984): "Time-Separable Preferences and IntertemporalSubstitution Models of Business Cycles," The Quarterly Journal of Economics, 99, 817-839.

Barsky, R., and E. Sims (2010): "Information, Animal Spirits, and the Meaning of Innovations in Consumer Confidence," mimeo.

Baxter, M., And R. KIng (1993): "Fiscal Policy in General Equilibrium," American Economic Review, 83(3), 315-34. 
Beaudry, P., And F. Portier (2004): "An Exploration into Pigou's Theory of Cycles," Journal of Monetary Economics, 51(6), 1183-1216.

Beaudry, P., And F. Portier (2007): "When can changes in expectations cause business cycle fluctuations in neo-classical settings?," Journal of Economic Theory, 135(1), 458-477.

Bilbiıe, F. (2011): "Nonseperable Preferences, Frisch Labor Supply, and the Consumption Multiplier of Government Spending: One Solution to Fiscal Policy Puzzle.," Journal of Monetary, Credit and Banking, 43(1).

Blanchard, O., and R. Perotti (2002): "An Empirical Characterization of the Dynamic Effects of Changes in Government Spending and Taxes on Output," Quarterly Journal of Economics, 117, 1329-68.

Blundel, R., L. Pistaferri, and I. Preston (2009): "Consumption Inequality and Partial Insurance," American Economic Review, 98(5), 1887-1921.

Burnside, C., M. Eichenbaum, And J. D. M. Fisher (2004): "Fiscal shocks and their consequences," Journal of Economic Theory, 115(1), 89-117.

Carrol, C. (2003): "Macroeconomic Expectations of Households and Professional Fore- casters," Quarterly Journal of Economics, 118(1), 269-298.

Cochrane, J. (1991): "A critique of the application of unit root tests," Journal of Economic Dynamics and Control, 15, 275-284.

Den Haan, W. J., and G. Kaltenbrunner (2009): "Anticipated Growth and Business Cycles in Matching models," Journal of Monetary Economics., 56(3), 309-327.

Dynarski, S., And J. Gruber (1997): “Can Families Smooth Variable Earnings?,” Brookings Papers on Economic Activity, 1, 229-303.

Eusepi, S., And B. Preston (2009): "Labor Supply Heterogeneity and Macroeconomic Comovement," NBER Working Papers 15561, National Bureau of Economic Research, Inc.

Farmer, R., And J. Guo (1995): "The Econometrics of Indeterminacy: An Applied Study," Carnegie-Rochester Conference Series on Public Policy, 43, 225-271.

Fatas, A., And I. Minov (2001): "The Effects of Fiscal Policy on Consumption and Employment: Theory and Evidence," CEPR Discussion Papers 2760, C.E.P.R. Discussion Papers.

Galí, J. (2008): Monetary Policy, Inflation, and the Business Cycle: An Introduction to the New Keynesian Framework. Princeton University Press, Princeton, New Jersey.

Galí, J., J. D. López-Salido, and J. Vallés (2007): "Understanding the Effects of Government Spending on Consumption," Journal of the European Economic Association, 5(1), $227-270$.

Harrison, S., And M. Weder (2006): "Did Sunspot Forces Cause the Great Depression?," Journal of Monetary Economics, 53, 1327-1339. 
Jaimovich, N., and S. Rebelo (2009): "Can News about the Future Drive the Business Cycle?," American Economic Review, 99(4), 1097-1118.

Leduc, S., ANd K. Sill (2010): "Expectations and economic fluctuations: an analysis using survey data," Working Papers 10-6, Federal Reserve Bank of Philadelphia.

LiLien, D. (1982): "Sectoral Shifts and Cyclical Unemployment," Journal of Political Economy, 90, 777-793.

Ramey, V. A., And M. D. Shapiro (1998): "Costly capital reallocation and the effects of government spending," Carnegie-Rochester Conference Series on Public Policy, 48(1), 145194.

Schmitt-Grohé, S., And M. Uribe (2008): "What's News in Business Cycles," Working Paper 14215, NBER. 


\section{A Proofs}

Proof of Proposition 1: The first part of the proposition is shown to be satisfied by the example given in the main text. All that remains to be shown is that strong positive comovement is not possible. We will show this by contradiction. So let us assume that an increase in $\Omega_{1}$ leads to an increase in $C^{i}$ and $L^{i}$ for both agents 1 and 2 . When consumption and leisure are normal, this implies that the marginal rate of substitution between leisure and consumption $\frac{U_{2}^{i}\left(C^{i}, 1-L^{i}\right)}{U_{1}^{i}\left(C^{i}, 1-L^{i}\right)}$ increases for both agents. ${ }^{39}$ Without loss of generality, we can assume that agent 1 works in the consumption sector, and hence the condition $\frac{U_{2}^{i}\left(C^{i}, 1-L^{i}\right)}{U_{1}^{i}\left(C^{i}, 1-L^{i}\right)}=F_{1}^{C}\left(L^{C 1}, L^{C 2}\right)$ must hold and accordingly $F_{1}^{C}\left(L^{C 1}, L^{C 2}\right)$ must increase in response to an increase in $\Omega_{1}$. There are then two cases to consider, either agent 1 is the only agent working in the consumption sector or both agents are working in the consumption sector. If agent 1 is the only agent, then the marginal production in this sector is fixed due to CRS and hence we have a contradiction as the condition $\frac{U_{2}^{1}\left(C^{1}, 1-L^{1}\right)}{U_{1}^{1}\left(C^{1}, 1-L^{1}\right)}=F_{1}^{C}\left(L^{C 1}\right)$ cannot be satisfied if there is strong positive co-movement. If both agents work in the consumption sector, then we need $\frac{U_{2}^{i}\left(C^{i}, 1-L^{i}\right)}{U_{1}^{i}\left(C^{i}, 1-L^{i}\right)}=F_{i}^{C}\left(L^{C 1}, L^{C 2}\right)$ to hold for both agents, which implies that the marginal product must increase for each type of agent, that $F_{i}^{C}\left(L^{C 1}, L^{C 2}\right)$ must increase for $i$ equal 1 and 2 . But with the production function satisfying concavity and CRS, this is not possible. ${ }^{40}$

Proof of Proposition 2: There are two components to this proposition. First we need to show that with homogeneous labor, it is impossible to get positive co-movement. If labor is homogeneous, then $F_{1}^{c}\left(L^{C 1}+L^{C 2}\right)=P F_{1}^{K}\left(L^{K 1}+L^{K 2}\right)$. Since we are assuming that the production function satisfies constant returns to scale, this implies that the marginal products are constant. It therefore directly follows that $\frac{U_{2}^{i}\left(C^{i}, 1-L^{i}\right)}{U_{1}^{i}\left(C^{i}, 1-L^{i}\right)}$ must remain constant for each worker. Under the assumption that consumption and leisure are normal goods, this implies that $C^{i}$ and $L^{i}$ must move in opposite directions (or remain unchanged) in response to a change $\Omega_{1}$ and hence positive co-movement is impossible. The second part of the proposition can be shown by example. In particular, Example 1 in section 3.3 is a case with identical preferences in which changes in $\Omega_{1}$ cause individual positive co-movement and positive price-quantity co-movement.

Proof of Proposition 3: This proposition uses the demand functions $K^{i}\left(P, w^{i}, \Omega_{1}\right)$ and the supply functions $L^{i}\left(P, w^{i}, \Omega_{1}\right)$ to characterize the equilibrium. There are three equilibrium prices- $P, w^{1}$ and $w^{2}$ - that will adjust to equate demand and supply in the two labor markets and in the market for capital (the market for consumption goods will be cleared by Walras' Law). Given that agents are specialized, the type 1 worker can produce only the consumption good, and that the production function is one-to-one, then equilibrium in the type 1 labor market implies $w^{1}=1$. Similarly, given that type 2 can only produce the investment good,

$39 d \frac{U_{2}^{i}\left(C^{i}, 1-L^{i}\right)}{U_{1}^{i}\left(C^{i}, 1-L^{i}\right)}=\left[U_{1} U_{21}-U_{2} U_{11}\right] d C+\left[U_{2} U_{12}-U_{1} U_{22}\right] d L$. The two terms in brackets are precisely the conditions defining normal goods, hence $d C$ and $d L$ positive implies an increase in $\frac{U_{2}}{U_{1}}$.

${ }^{40}$ For both marginal products to increase we need $F_{11}^{C} d L^{C 1}+F_{12}^{C} d L^{C 2}>0$ and $F_{12}^{C} d L^{C 1}+F_{22}^{C} d L^{C 2}>0$. CRS implies that $F_{12}^{C}=-F_{11}^{C} \frac{L^{C 1}}{L^{C 2}}$ and $F_{12}^{C}=-F_{22}^{C} \frac{L^{C 2}}{L^{C 1}}$. This implies that we need $L_{1}^{C} F_{11}^{C}\left[\frac{d L^{C 1}}{L^{C 1}}-\frac{d L^{C 2}}{L^{C 2}}\right]>0$ $L^{C 2} F_{22}^{C}\left[\frac{d L^{C 2}}{L^{C 2}}-\frac{d L^{C 1}}{L^{C 1}}\right]>0$ which is impossible. 
equilibrium in the type 2 labor market implies that $w^{2}=P$. The equilibrium determination of $p$ is therefore determined by the condition

$$
K^{1}\left(P, 1 ; \Omega_{1}\right)+K^{2}\left(P, P ; \Omega_{1}\right)=L^{2}\left(P, P ; \Omega_{1}\right) .
$$

Hence the effect of $\Omega_{1}$ on $P$ is given by

$$
\frac{d P}{d \theta}=\frac{L_{3}^{2}-K_{3}^{2}-K_{3}^{1}}{K_{1}^{2}+K_{2}^{2}+K_{1}^{1}-L_{1}^{2}-L_{2}^{2}} .
$$

To sign this effect, we need to look at properties of the demand functions. These will depend on on four terms $\Lambda, \chi, \Gamma, \Delta$ which are defined as follows (where subscripts represent derivative)

$$
\begin{gathered}
\Lambda \equiv U_{22} U_{11}-U_{12}^{2}, \\
\chi=w^{2} U_{11}-2 w U_{12}+U_{22},
\end{gathered}
$$

where concavity implies that $\Lambda$ is positive and $\chi$ is negative. Furthermore, since $C$ and $(1-L)$ are normal goods, this implies that:

$$
\begin{gathered}
\Gamma \equiv w U_{11}-U_{12}<0 \\
\Delta \equiv w U_{12}-U_{22}>0 .
\end{gathered}
$$

Given these definition, the derivative of the demand functions are given as follows

$$
\begin{aligned}
L_{1} & =\frac{\Gamma\left(V_{11} K+V_{1}\right)}{p^{2} \Lambda+\chi V_{11}} \gtreqless 0, \\
K_{1} & =\frac{\chi U_{1}-p K \Lambda}{p^{2} \Lambda+\chi V_{11}}<0, \\
L_{2} & =-\frac{\Gamma l V_{11}+U_{1}\left(p^{2} U_{11}+V_{11}\right)}{p^{2} \Lambda+\chi V_{11}} \gtreqless 0, \\
K_{2} & =\frac{p\left(l \Lambda-\Gamma U_{1}\right)}{p^{2} \Lambda+\chi V_{11}}>0, \\
L_{3} & =-\frac{p \Gamma V_{12}}{p^{2} \Lambda+\chi V_{11}}>0, \\
K_{3} & =-\frac{\chi V_{12}}{p^{2} \Lambda+\chi V_{11}}>0 .
\end{aligned}
$$

Therefore we have

$$
\begin{aligned}
L_{3}^{2}-K_{2}^{2} & =\frac{(\chi-P \Gamma) V_{12}}{P^{2} \Lambda+\chi V_{11}}, \\
& =\frac{-\Delta V_{12}}{P^{2} \Lambda+\chi V_{11}}<0,
\end{aligned}
$$

so the numerator on the RHS of (A.1) is negative. The assumptions in the Proposition assure that the denominator is negative. Hence under the conditions of the proposition we have

$$
\frac{d P}{d \Omega_{1}}>0
$$


To examine the effects of an increase in $\Omega_{1}$ on consumption, investment and employment we now need to examine if $L^{1}$ and $L^{2}$ increase with $\Omega_{1}$, taking into account its effect on equilibrium prices. Hence for positive co-movement we need

$$
L_{1}^{1} \frac{d P}{d \Omega_{1}}+L_{3}^{1}>0, \quad\left(L_{1}^{2}+L_{2}^{2}\right) \frac{d P}{d \Omega_{1}}+L_{3}^{2}>0 .
$$

Since $L_{3}^{i}>0$, then by the assumptions of the proposition we have that an increase in $\Omega_{1}$ leads to positive co-movement.

Proof of Proposition 4: With ex-ante trading in claims dependent on $\Omega_{1}$, the agent's first order conditions are of the form

$$
\begin{gathered}
\Pi_{m} U_{1}^{i}\left(C_{m}^{i}, 1-L_{m}^{i}\right)=\lambda^{i} p_{m}^{c} \\
\Pi_{m} U_{2}^{i}\left(C_{m}^{i}, 1-L_{m}^{i}\right)=\lambda^{i} w_{m}^{i}, \\
\Pi_{m} V_{1}^{i}\left(K_{m}^{i}, \Omega_{1}\right)=\lambda^{i} p_{m}^{k}
\end{gathered}
$$

where $\lambda^{i}$ is the multiplier related to agent $i$ 's budget set. If labor is homogeneous, then $p_{m}^{c}=w_{m}^{i}$ for $i=1,2$, and therefore

$$
\frac{U_{1}^{i}\left(C_{m}^{i}, 1-L_{m}^{i}\right)}{U_{2}^{i}\left(C_{m}^{i}, 1-L_{m}^{i}\right)}=1
$$

Hence, because goods are normal, consumption and labor have to move in opposite directions and therefore positive co-movement induced by realizations of $\Omega_{1}$ is not possible.

If agents are specialized, then for the agent in the consumption good sector, it will again be the case that $\frac{U_{1}^{i}\left(C_{m}^{i}, 1-L_{m}^{i}\right)}{U_{2}^{i}\left(C_{m}^{i}, 1-L_{m}^{i}\right)}=1$ and hence his consumption cannot increase if his employment increases. Further, we have the risk sharing condition that implies that the marginal utility of consumption must move in the same direction for both types of agents. Under separable preferences, this implies that consumption of both types must move in tandem. Given that the consumption of the type working in the consumption sector can increase with an increase in his labor, this implies that aggregate consumption does not move with a change in $\Omega_{1}$ hence positive co-movement is not possible.

Proof of Proposition 5: When labor is homogeneous, an increase in government purchases of investment goods will not change marginal products. Hence, normality implies that $C^{i}$ and $L^{i}$ must move in opposite directions and therefore positive co-movement is not possible as employment will need to decrease for at least one type of labor if consumption is to increase.

Proof of Proposition 6: For this proposition, we will work with the demand functions $K^{i}\left(p, w^{i}, \Omega_{1}, T^{i}\right)$ and the labor supply function $L^{i}\left(p, w^{i}, \Omega_{1}, T^{i}\right)$ where these functions are defined as the solution to

$$
\max _{C^{i}, K^{i}, L^{i}} U^{i}\left(C^{i}, 1-L^{i}\right)+V^{i}\left(K^{i}, \Omega_{1}\right)
$$

subject to

$$
C^{i}+P K^{i}=w^{i} L^{i}-T^{i}
$$


Under the maintained assumptions on utility, these functions continue to have the properties spelled out in the proof of Proposition 3. In addition, it is easy to verify that $L_{4}^{i}>0, K_{4}^{i}>0$, $0>p K_{4}^{i}>1$ and $1>\left(L_{4}^{2}-K_{4}^{2}\right)>0$. Therefore, to verify the proposition all we need is to check that $\frac{d P}{d G}>0$, where $P$ solves the capital market equilibrium condition given by

$$
K^{1}\left(P, 1, \Omega_{1}, T^{1}\right)+K^{2}\left(P, P, \Omega_{1}, T^{2}\right)+G=L^{2}\left(P, P, \Omega_{1}, T^{2}\right) .
$$

When $T^{1}=\alpha P G$ and $T^{2}=(1-\alpha) P G$, we have

$$
\frac{d P}{d \theta}=\frac{L_{4}^{2}(1-\alpha) P-1-K_{4}^{2}(1-\alpha) P-K_{4}^{1} \alpha P}{K_{1}^{2}+K_{2}^{2}+K_{4}^{2}(1-\alpha) P+K_{1}^{1}+K_{4}^{1} \alpha P-L_{1}^{2}-L_{2}^{2}-L_{4}^{2}(1-\alpha) P} .
$$

The properties of the demand functions imply that numerator of this expression is negative, and the assumptions of the proposition $\left(K_{1}^{2}+K_{2}^{2}+K_{1}^{1}<0, L_{1}^{2} \geq 0\right.$ and $\left.L_{2}^{2} \geq 0\right)$ again combined with the properties of the demand functions imply that the denominator is negative, hence $\frac{d P}{d G}>0$.

To examine whether an increase in $G$ (on investment) leads to an increase in total investment we need to examine the sign of

$$
\left(L_{1}^{2}+L_{2}^{2}+L_{4}^{2}(1-\alpha) G\right) \frac{d P}{d G}+L_{4}^{2}(1-\alpha) P .
$$

The assumptions of the proposition (regarding labor supply) and the properties of the labor supply function imply that this term is positive.

To examine whether an increase in $G$ (on investment) does not lead to an increase in private investment we need to examine the sign of

$$
\left(K_{1}^{1}+K_{4}^{1} \alpha G+K_{1}^{2}+K_{2}^{2}+K_{4}^{2}(1-\alpha) G\right) \frac{d P}{d G}+K_{4}^{1} \alpha P+K_{2}^{1}(1-\alpha) P .
$$

The assumptions of the proposition (regarding capital demand) and the properties of the labor supply function imply that this term is negative.

Finally to examine whether the fiscal policy leads to an increase in the production of consumption good we need to examine the sign of

$$
\left(L_{1}^{1}+L_{4}^{1} \alpha G\right) \frac{d P}{d G}+L_{4}^{1} \alpha P .
$$

The assumptions of the proposition (regarding labor supply) and the properties of the labor supply function imply that this term is positive. Hence, an increase in Government expenditures on investment goods causes positive co-movement, with a positive spillover effect on consumption but a negative effect on private investment (no amplification).

\section{B Data}

In Table B.1, we present the correspondence we used to match industries between NIPA and PSID. 
Table B.1: Correspondence between Industries in NIPA tables and Industry Codes in the PSID

\begin{tabular}{lcccc}
\hline \hline Industry & $\begin{array}{c}\text { SIC-72 \& SIC-87 } \\
\text { Line Number } \\
\text { (NIPA Tables) }\end{array}$ & $\begin{array}{c}\text { NAICS } \\
\text { Line Number } \\
\text { (NIPA Tables) }\end{array}$ & $\begin{array}{c}1970 \text { COC } \\
(1 \text { or 2 dig) } \\
\text { (PSID) }\end{array}$ & $\begin{array}{c}2000 \text { COC } \\
(3 \text { dig) } \\
\text { (PSID) }\end{array}$ \\
\hline \hline Ag., Forest, Fish & 4 & 4 & 1 & $017-029$ \\
\hline Mining & 7 & 7 & 2 & $037-049$ \\
\hline Construction & 12 & 12 & 3 & 077 \\
\hline Manufacturing & 13 & 13 & 4 & $107-399$ \\
\hline Transp., Comm. Publ U. & 37 & 11,43 & 5 & $607-639,647-679$ \\
& & 52 & 5 & $607-639,647-679$ \\
\hline Wholesale Trade & 50 & 35 & 62 & $407-459$ \\
\hline Retail Trade & 51 & 38 & 61 & $467-579$ \\
\hline Fin., Ins., R. Estate & 52 & 57,62 & 7 & $687-719$ \\
Services & 60 & $65,69,70$, & $8-11$ & $727-929$ \\
& & 82,85 & & \\
\hline Government & 76 & 82,85 & & $937-959$ \\
\hline
\end{tabular}

\section{Analytical steps of A New Keynesian model with ex- plicit gains from trade (not for publication)}

Let us consider a simple New Keynesian model that we augment to include explicit gains from trade between individuals. Some agents will produce the consumption good and some the investment good. Although we allow for capital accumulation and agents heterogeneity, we will make functional forms assumptions to preserve tractability of the model. The model will have the basic New Keynesian model of Galí [2008] as a special case.

\section{C.1 Fundamentals}

\section{C.1.1 Preferences}

The economy is populated by $n_{C}$ consumption good workers and $n_{X}$ investment good workers. All agents consume an aggregate consumption good, that is a basket of monopolistically produced consumption goods indexed by $j$. Denoting $c_{C t}$ and $c_{X t}$ the consumption of a representative consumption good worker and of a representative investment good worker, we have:

$$
\begin{aligned}
& c_{C t}=\left(\int_{0}^{1} c_{C j t}^{\frac{\varepsilon-1}{\varepsilon}} d j\right)^{\frac{\varepsilon}{\varepsilon-1}}, \\
& c_{X t}=\left(\int_{0}^{1} c_{X j t}^{\frac{\varepsilon-1}{\varepsilon}} d j\right)^{\frac{\varepsilon}{\varepsilon-1}} .
\end{aligned}
$$

with $\varepsilon>1$. Consumption workers are all identical, infinitely lived and have preferences over consumption and leisure given by

$$
\sum \beta^{t}\left(\ln \left(c_{c t}\right)+\Phi\left(1-\ell_{C t}\right)\right)
$$


with $1>\beta>0$ and $\Phi>0$. For simplicity, investment workers are myopic, and do not make intertemporal choices: they do not own any assets nor have any liabilities, and just consume their current labor income. Their preferences are given by

$$
U\left(c_{X t}-\Psi \frac{\ell_{X t}^{1+\gamma}}{1+\gamma}\right)
$$

with $\gamma>0$ and where $U$ is a concave and $C^{2}$ function.

\section{C.1.2 Technologies}

Each monopoly $j$ produces a variety of consumption good according to the following constant return to scale technology:

$$
C_{j t}=\Theta_{t} K_{j t}+A_{t} L_{C t} .
$$

Capital and labor are perfectly substitutable in the production of consumption good varieties, which allow for an easier analytical solution. $\Theta_{t}$ is a capital specific stochastic technological shocks and $A_{t}$ a labor specific one. ${ }^{41}$ For simplicity, these are the only source of uncertainty in the model.

The investment good is produced by a representative competitive firm, with labor only, and according to the constant return to scale technology:

$$
X_{t}=B L_{X t}
$$

Capital accumulates according to the following law of motion, with $\delta \in[0,1]$ :

$$
K_{t+1}=(1-\delta) K_{t}+X_{t}
$$

\section{C.1.3 Markets organization}

There is a monopoly for each variety of the consumption good. Labor, investment good, bonds and money markets are competitive. Money is the numéraire. Total real output (or real GDP) is measured in units of consumption and is defined as

$$
Y_{t}=C_{t}+\frac{R_{t}}{P_{t}} X_{t}
$$

where $P_{t}$ is the consumption goods price index and $R_{t}$ is the price of the investment good.

\section{C.1.4 Price setting}

When prices are sticky, we assume Calvo price setting. In order to embed the standard model of Galí as a special case of our model when $n_{X}=0$, we assume that prices are sticky in the consumption good sector only. Each consumption firm may reset its price with probability $1-\theta, \theta \in[0,1]$. In the investment good sector, we maintain the assumption of flexible prices.

\footnotetext{
${ }^{41}$ One can allow for a correlation between $\Theta$ and $A$, to account for total factor productivity shocks.
} 


\section{C.1.5 Monetary authorities}

The central bank sets the nominal interest rate following a Taylor rule.

\section{C.2 Households}

\section{C.2.1 Consumption worker}

The representative consumption worker maximizes expected utility $E_{0}\left[\sum_{t=0}^{\infty} \beta^{t}\left(\ln c_{C t}+\Phi\left(1-\ell_{C t}\right)\right)\right]$ subject to the budget constraint:

$$
P_{t} c_{C t}+R_{t} k_{t+1}+Q_{t} b_{t} \leq\left((1-\delta) R_{t}+Z_{t}\right) k_{t}+W_{C t} \ell_{C t}+t_{C t}+B_{t-1},
$$

with

$$
\begin{aligned}
P_{t} c_{C t} & =\int_{0}^{1} P_{j t} c_{C j t} d j \\
c_{C t} & =\left(\int_{0}^{1} c_{C j t}^{\frac{\varepsilon-1}{\varepsilon}} d j\right)^{\frac{\varepsilon}{\varepsilon-1}}, \\
P_{t} & =\left(\int_{0}^{1} P_{j t}^{1-\varepsilon} d j\right)^{\frac{1}{1-\varepsilon}},
\end{aligned}
$$

where $Z_{t}$ is the rental rate of capital, $W_{C t}$ is the wage in the consumption good sector and $t_{C t}$ collects lump sum transfers (including monopolies profits).

First order conditions to this problem are

$$
\begin{aligned}
c_{C j t} & =\left(\frac{P_{j t}}{P_{t}}\right)^{-\varepsilon} c_{C t}, \\
c_{C t} & =\Phi-\frac{W_{C t}}{P_{t}} \\
Q_{t} & =\beta E_{t}\left[\frac{c_{C t}}{c_{C t+1}} \frac{P_{t}}{P_{t+1}}\right], \\
R_{t} & =\beta E_{t}\left[\frac{c_{C t}}{c_{C t+1}} \frac{P_{t}}{P_{t+1}}\left((1-\delta) R_{t+1}+Z_{t+1}\right)\right] .
\end{aligned}
$$

\section{C.2.2 Investment worker}

The representative investment worker maximizes utility $U\left(c_{X t}-\Psi \frac{\ell_{X t}^{1+\gamma}}{1+\gamma}\right)$ subject to the budget constraint:

$$
P_{t} c_{X t} \leq W_{X t} \ell_{X t}
$$

with

$$
\begin{aligned}
P_{t} c_{X t} & =\int_{0}^{1} P_{j t} C_{X j t} d j \\
c_{X t} & =\left(\int_{0}^{1} \frac{c_{X j t}^{\frac{\varepsilon-1}{\varepsilon}}}{c^{\varepsilon}} d j\right)^{\frac{\varepsilon}{\varepsilon-1}} .
\end{aligned}
$$


and the first order condition are

$$
\begin{aligned}
c_{X j t} & =\left(\frac{P_{j t}}{P_{t}}\right)^{-\varepsilon} c_{X t}, \\
\Psi \ell_{X t}^{\gamma} & =\frac{W_{X t}}{P_{t}}
\end{aligned}
$$

\section{C.3 Firms}

\section{C.3.1 Investment good firms}

Firms are competitive, and maximize profits $R_{t} X_{t}-W_{I t} L_{I t}$ subject to the technological constraint $X_{t}=B L_{I t}$. The first order condition is:

$$
W_{X t}=B R_{t}
$$

\section{C.3.2 Consumption good firms}

When prices are flexible $(\theta=0)$, firm $j$ (that produces variety $j$ ) maximizes profit $P_{j t} C_{j t}-$ $Z_{t} K_{j t}-W_{C t} L_{C t}$ subject to technological constraint $C_{j t}=\Theta_{t} K_{j t}+A_{t} L_{C j t}$ and demand $c_{X j t}=$ $\left(\frac{P_{j t}}{P_{t}}\right)^{-\varepsilon} c_{X t}$. First order conditions are:

$$
\begin{aligned}
P_{j t} & =\mathcal{M} \frac{Z_{t}}{\Theta_{t}}, \\
P_{j t} & =\mathcal{M} \frac{W_{C t}}{A_{t}},
\end{aligned}
$$

with $\mathcal{M}=\frac{\varepsilon}{\varepsilon-1}$.

When prices are sticky $(\theta>0)$, the firm maximizes expected discounted sum of profits (see Galí [2008], chapter 3 for details), and optimal pricing behavior is given by

$$
\sum_{k=0}^{\infty} \theta^{k} E_{t}\left[Q_{t, t+k} \bar{C}_{t, t+k}\left(P_{t}^{\star}-\mathcal{M N}_{t+k, t}\right)\right]=0
$$

where $Q_{t, t+k}=\beta^{k}\left(c_{C t+k} / c_{C t}\right)\left(P_{t} / P_{t+k}\right)$ is the nominal stochastic discount factor, $\bar{C}_{t, t+k}$ is the production of a firm that last reset its price in period $t$ and $\mathcal{N}_{t+k, t}$ is the nominal marginal cost for a firm that last reset its price in period $t$. 


\section{C.4 Flexible price equilibrium $(\theta=0)$}

\section{C.4.1 Solution}

When prices are flexible, the intertemporal equilibrum is given the following set of equations

$$
\begin{aligned}
& C_{C t}=n_{C} \Phi^{-1} \frac{W_{C t}}{P_{t}} \\
& R_{t}=\beta E_{t}\left[\frac{C_{C t}}{C_{C t+1}} \frac{P_{t}}{P_{t+1}}\left((1-\delta) R_{t+1}+Z_{t+1}\right)\right], \\
& Q_{t}=\beta E_{t}\left[\frac{C_{C t}}{C_{C t+1}} \frac{P_{t}}{P_{t+1}}\right] \\
& C_{t}=C_{C t}+C_{X t}, \\
& C_{t}=\Theta_{t} K_{t}+A_{t} L_{C t}, \\
& \Psi n_{X}^{-\gamma} L_{X t}^{\gamma}=\frac{W_{X t}}{P_{t}} \\
& C_{X t}=\frac{W_{X t}}{P_{t}} L_{X t}, \\
& W_{X t}=B R_{t}, \\
& X_{t}=B L_{K t}, \\
& P_{t} \Theta_{t}=\mathcal{M} Z_{t}, \\
& P_{t} A_{t}=\mathcal{M} W_{C t}, \\
& K_{t+1}=(1-\delta) K_{t}+X_{t}, \\
& Y_{t}=C_{t}+\frac{R_{t}}{P_{t}} X_{t},
\end{aligned}
$$

with $C_{C t}=n_{C} c_{C t}, C_{X t}=n_{X} c_{X t}, L_{C t}=n_{C} \ell_{C t}, L_{X t}=n_{X} \ell_{X t}, K_{t}=n_{C} k_{C t}$ and $T_{C t}=n_{C} t_{C t}$.

From (C.2) and (C.12), on obtains

$$
C_{C t}=n_{C}(\mathcal{M} \Phi)^{-1} A_{t}
$$

Note that only $A_{t}$ (and not $\Theta_{t}$ ) enters in the consumption worker's consumption, which will happen to be very convenient for tractability when comparing with the sticky prices allocations. This is of course not a general result. Using (C.11), (C.3) becomes

$$
\frac{R_{t}}{P_{t}}=\beta E_{t}\left[\left(\frac{C_{c t}}{C_{c t+1}}\right)\left((1-\delta) \frac{R_{t+1}}{P_{t+1}}+\mathcal{M}^{-1} \Theta_{t+1}\right)\right]
$$

The real price (in units of the consumption good) of one unit of investment equals its next period discounted marginal productivity and resale price net of depreciation. Using the expression of $C_{c t}$ obtained in (C.15), we get

$$
\frac{R_{t}}{A_{t} P_{t}}=\beta E_{t}\left[(1-\delta) \frac{R_{t+1}}{A_{t+1} P_{t+1}}+\mathcal{M}^{-1}\left(\frac{\Theta_{t+1}}{A_{t+1}}\right)\right] .
$$


Solving forward, we obtain the solution for the price of investment:

$$
\frac{R_{t}}{P_{t}}=A_{t} \mathcal{M}^{-1} \sum_{j=1}^{\infty} \beta^{j}(1-\delta)^{j-1} E_{t}\left[\frac{\Theta_{t+j}}{A_{t+j}}\right]
$$

Once the real price of investment is obtained, the rest of the model can be recursively solved as all the other variables are statically related to the real price of investment.

\section{C.4.2 Log-linear approximation}

It is useful to write the model solution when a log-linear approximation around the non stochastic steady state is taken. Using a hat for log deviations from the steady state and with the notation $z=Z / P$ and $r=R / P$, equation (C.3) becomes

$$
\left(\widehat{r}_{t}-\widehat{c}_{C t}\right)=\beta(1-\delta) E_{t}\left[\widehat{r}_{t+1}-\widehat{c}_{c t+1}\right]+(1-\beta(1-\delta)) E_{t}\left[\widehat{z}_{t+1}-\widehat{c}_{c t+1}\right] .
$$

(C.2) and (C.12) give $\widehat{c}_{C t}=\widehat{A}_{t}$ and (C.11) gives $\widehat{z}_{t}=\widehat{\Theta}_{t}$. Substituting in (C.18) and solving forward, we obtain

$$
\widehat{r}_{t}=\widehat{A}_{t}+\left((1-\beta(1-\delta)) \sum_{j=0}^{\infty}(\beta(1-\delta))^{j} E_{t}\left[\widehat{\Theta}_{t+i+1}-\widehat{A}_{t+i+1}\right] .\right.
$$

Denoting by $\chi=\frac{C_{C}}{C}$ the steady state share of the consumption worker's consumption in total consumption and by $s_{c}=\frac{C}{Y}$ the share of consumption in GDP, we have the following expressions for aggregate consumption and real GDP:

$$
\begin{aligned}
& \widehat{c}_{t}=\chi \widehat{c}_{C t}+(1-\chi) \widehat{c}_{X t}, \\
& \widehat{y}_{t}=s_{c} \widehat{c}_{t}+\left(1-s_{c}\right)\left(\widehat{r}_{t}+\widehat{x}_{t}\right) .
\end{aligned}
$$

Using (C.8), (C.9) and (C.10), we obtain an expression of $X_{t}$ as a function of $\frac{R_{t}}{p_{t}}$. Note that trade between the two type of agents is made apparent by observing that the budget constraint of the investment worker is

$$
C_{X t}=\frac{R_{t}}{P_{t}} X_{t}
$$

Using (C.20), (C.21) and (C.22), we obtain

$$
\widehat{y}_{t}=s_{c} \chi \widehat{c}_{C t}+\left(1-s_{c} \chi\right)\left(\frac{1+\gamma}{\gamma}\right) \widehat{r}_{t} .
$$

Putting all this together and log-linearizing, the flexible price allocations are given by (where a $n$ supperscript represents natural as meaning the "flexible price allocations")

$$
\left\{\begin{aligned}
\gamma \widehat{y}_{t}^{n}= & \beta \gamma(1-\delta) E_{t} \widehat{y}_{t+1}^{n}+\left(1-s_{c} \chi\right)(1+\gamma)(1-\beta(1-\delta)) E_{t}\left[\widehat{\Theta}_{t+1}-\widehat{A}_{t+1}\right] \\
& -\beta(1-\delta)\left(\gamma+1-s_{c} \chi\right) E_{t} \widehat{A}_{t+1} \\
\widehat{\rho}_{t}^{n}= & \widehat{\imath}_{t}-E_{t} \widehat{\pi}_{t+1}=E_{t} \widehat{A}_{t+1}-\widehat{A}_{t} \\
+ & \text { Taylor rule }
\end{aligned}\right.
$$


where $i_{t}=-\log Q_{t}$ is the nominal interest rate and $\rho_{t}$ the real interest rate..

Note that solving forward, we can write natural output as

$$
\widehat{y}_{t}^{n}=\sum_{j=0}^{\infty} \phi_{1}(j) E_{t}\left[\widehat{\Theta}_{t+1+j}-\widehat{A}_{t+1+j}\right]+\sum_{j=0}^{\infty} \phi_{2}(j) E_{t}\left[A_{t+j}-\beta(1-\delta) \widehat{A}_{t+1+j}\right],
$$

with $\phi_{1}(j)=\left(1-s_{c} \chi\right)\left(\frac{1+\gamma}{\gamma}\right)(1-\beta(1-\delta))(\beta(1-\delta))^{j}$ and $\phi_{2}(j)=\left(\frac{1+\gamma-s_{c} \chi}{\gamma}\right)(\beta(1-\delta))^{j}$. Note that we have, $\forall j \geq 0, \frac{\partial \widehat{y}_{t}^{n}}{\partial \widehat{A}_{t}}>0, \frac{\partial \widehat{y}_{t}{ }^{n}}{\partial \widehat{A}_{t+1}}<0, \frac{\partial \widehat{y}_{t}{ }^{n}}{\partial \widehat{\Theta}_{t+1}}=0$ and $\frac{\partial \widehat{y}_{t}^{n}}{\partial \widehat{\Theta}_{t+1}}>0$.

\section{C.5 Sticky price equilibrium $(\theta>0)$}

\section{C.5.1 Solution}

With Calvo pricing, (consumption price) inflation $\Pi_{t}=\frac{P_{t}}{P_{t-1}}$ will evolve according to

$$
\Pi_{t}^{1-\varepsilon}=\theta+(1-\theta)\left(\frac{P_{t}^{\star}}{P_{t-1}}\right)
$$

where $P_{t}^{\star}$ is the optimal price set by a firm reoptimizing in period $t$.

The intertemporal equilibrum is given the following set of equations

$$
\begin{aligned}
C_{C t} & =n_{C} \Phi^{-1} \frac{W_{C t}}{P_{t}}, \\
R_{t} & =\beta E_{t}\left[\frac{C_{C t}}{C_{C t+1}} \frac{P_{t}}{P_{t+1}}\left((1-\delta) R_{t+1}+Z_{t+1}\right)\right], \\
Q_{t} & =\beta E_{t}\left[\frac{C_{C t}}{C_{C t+1}} \frac{P_{t}}{P_{t+1}}\right], \\
C_{t} & =C_{C t}+C_{X t}, \\
C_{t} & =\Theta_{t} K_{t}+A_{t} L_{C t}, \\
\Psi n_{X}^{-\gamma} L_{X t}^{\gamma} & =\frac{W_{X t}}{P_{t}}, \\
C_{X t} & =\frac{W_{X t}}{P_{t}} L_{X t}, \\
W_{X t} & =B R_{t}, \\
X_{t} & =B L_{K t}, \\
P_{t} \Theta_{t} & =\mathcal{M}_{t} Z_{t}, \\
P_{t} A_{t} & =\mathcal{M}_{t} W_{C t}, \\
K_{t+1} & =(1-\delta) K_{t}+X_{t}, \\
Y_{t} & =C_{t}+\frac{R_{t}}{P_{t}} X_{t}, \\
\Pi_{t}^{1-\varepsilon} & =\theta+(1-\theta)\left(\frac{P_{t}^{\star}}{P_{t-1}}\right), \\
\sum_{k=0}^{\infty} \theta^{k} & E_{t}\left[Q_{t, t+k} \bar{C}_{t, t+k}\left(P_{t}^{\star}-\mathcal{M} \mathcal{N}_{t+k, t}\right)\right]=0 .
\end{aligned}
$$


Note that the markup $\mathcal{M}_{t}$ which is constant when prices are fully flexible is now time varying.

\section{C.5.2 Optimal pricing}

Solving for a log-linear version of (C.1), and using the fact that there are constant returns in the production of the consumption goods, one obtains

$$
\widehat{\pi}_{t}=\beta E_{t} \widehat{\pi}_{t+1}+\lambda \widehat{m c}_{t},
$$

with $\lambda=\frac{(1-\theta)(1-\beta \theta)}{\theta}$, where $\widehat{m c}$ is the real marginal cost log deviation from steady state in the consumption good sector and $\widehat{\pi}_{t}$ the $\log$ deviation of inflation $P_{t} / P_{t-1}$. Note that inflation here CPI inflation. The average real marginal cost is given by

$$
\widehat{m c}_{t}=\widehat{w}_{C t}-\widehat{p}_{t} .
$$

Using (C.25) and (C.35), we get

$$
\widehat{m c}_{t}=\widehat{c}_{C t}-\widehat{A}_{t}
$$

so that (C.40) becomes

$$
\widehat{\pi}_{t}=\beta E_{t} \widehat{\pi}_{t+1}+\lambda\left(\widehat{c}_{C t}-\widehat{A}_{t}\right)
$$

\section{C.5.3 Log-linear approximation}

Equations (C.25), (C.34) and (C.35) gives $\widehat{z}_{t}=\widehat{\Theta}_{t}-\widehat{\mathcal{M}}_{t}$ and $\widehat{c}_{c t+1}=\widehat{A}_{t}-\widehat{\mathcal{M}}_{t}$, so that $\widehat{z}_{t}-\widehat{c}_{C t}=$ $\widehat{\Theta}_{t}-\widehat{A}_{t}$. Note that $\widehat{z}_{t}-\widehat{c}_{C t}$ takes the same value in both the flexible and sticky price cases. Therefore, using (C.18) and using the $n$ subscript for the flexible price allocations ( $n$ for natural), we obtain

$$
\widehat{r}_{t}-\widehat{r}_{t}^{n}=\widehat{c}_{C t}-\widehat{A}_{t} \text {. }
$$

Let us define the output gap $\widetilde{y}_{t}=\widehat{y}_{t}-\widehat{y}_{t}^{n}$. Using (C.23) (that holds both in the flexible and sticky prices cases), we obtain

$$
\widetilde{y}_{t}=\zeta\left(\widehat{c}_{C t}-\widehat{A}_{t}\right)
$$

with $\zeta=\frac{1-s_{c} \chi+\gamma}{\gamma}$. From this equation, we obtain an expression for $\left(\widehat{c}_{C t}-\widehat{A}_{t}\right)$ that we substitute in (C.41) to obtain a typical New Keynesian Phillips curve:

$$
\widehat{\pi}_{t}=\beta E_{t} \widehat{\pi}_{t+1}+\lambda \zeta^{-1} \widetilde{y}_{t} .
$$

Furthermore, the log-linear approximation of equation (C.26) gives

$$
\widehat{c}_{C t}=E_{t} \widehat{c}_{C t+1}-\left(\widehat{\imath}_{t}-E_{t} \widehat{\pi}_{t+1}\right) .
$$

Using again equation (C.43), we obtain the dynamic IS equation

$$
\widetilde{y}_{t}=-\zeta\left(\widehat{\imath}_{t}-E_{t} \widehat{\pi}_{t+1}-\widehat{\rho}_{t}^{n}\right)+E_{t} \widetilde{y}_{t+1} .
$$

To summarize, allocations of the sticky price model are the given by

$$
\left\{\begin{aligned}
\widetilde{y}_{t}= & -\zeta\left(\widehat{\imath}_{t}-E_{t} \widehat{\pi}_{t+1}-\widehat{\rho}_{t}^{n}\right)+E_{t} \widetilde{y}_{t+1}, \\
\widehat{\pi}_{t}=\beta E_{t} \widehat{\pi}_{t+1}+\lambda \zeta^{-1} \widetilde{y}_{t}, & \text { Taylor rule. }
\end{aligned}\right.
$$


Using (C.24), the Phillips curve can be written as

$\widehat{\pi}_{t}=\beta E_{t} \widehat{\pi}_{t+1}+\lambda \zeta^{-1}\left(\widetilde{y}_{t}-\sum_{j=0}^{\infty} \phi_{1}(j) E_{t}\left[\widehat{\Theta}_{t+1+j}-\widehat{A}_{t+1+j}\right]-\sum_{j=0}^{\infty} \phi_{2}(j) E_{t}\left[\widehat{A}_{t+j}-\beta(1-\delta) \widehat{A}_{t+1+j}\right]\right)$.

Note that when one assumes full depreciation $(\delta=1)$, one has $\phi_{1}(0)=\left(1-s_{c} \chi\right)\left(\frac{1+\gamma}{\gamma}\right)$, $\phi_{2}(0)=\left(\frac{1+\gamma-s_{c} \chi}{\gamma}\right)$ and $\phi_{1}(j)=\phi_{2}(j)=0$ for $j \geq 1$. Therefore, natural output is given by

$$
\widehat{y}_{t}^{n}=\phi_{2}(0) A_{t}+\phi_{1}(0) E_{t}\left[\widehat{\Theta}_{t+1}-\widehat{A}_{t+1}\right]
$$

and the Phillips curve becomes

$$
\widehat{\pi}_{t}=\beta E_{t} \widehat{\pi}_{t+1}+\lambda \zeta^{-1}\left(\widetilde{y}_{t}-\phi_{2}(0) A_{t}-\phi_{2}(0) E_{t}\left[\widehat{\Theta}_{t+1}-\widehat{A}_{t+1}\right]\right) .
$$

\section{C.6 Obtaining the basic New Keynesian model}

If we assume that there are no investment workers $\left(n_{X}=0\right)$, then no investment is produced $\left(X_{t}=0\right)$ and no capital is used in the production of consumption varieties. Therefore, we are back to the standard model with $\widehat{y}_{t}=\widehat{c}_{t}=\widehat{c}_{C t}$. In the flexible price allocations, labor is constant, so that natural output is given by $\widehat{y}_{t}^{n}=\widehat{A}_{t}$ and the natural real interest rate $\widehat{\rho}_{t}^{n}=E_{t} \widehat{A}_{t+1}-\widehat{A}_{t}$.

The model solution is then given by the standard three equations:

$$
\left\{\begin{array}{l}
\widetilde{y}_{t}=E_{t} \widetilde{y}_{t+1}-\left(\widehat{\imath}_{t}-E_{t} \widehat{\pi}_{t+1}-\widehat{\rho}_{t}^{n}\right) \\
\widehat{\pi}_{t}=\beta E_{t} \widehat{\pi}_{t+1}+\lambda \widehat{y}_{t} \\
+\quad \text { Taylor rule. }
\end{array}\right.
$$

